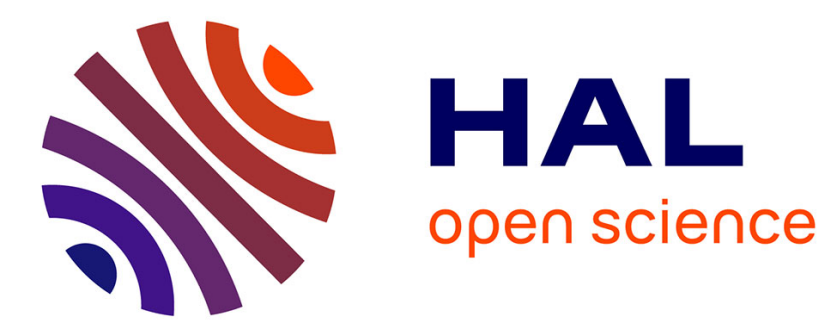

\title{
Mitigation strategies and energy technology learning: an assessment with the POLES model
}

\author{
Patrick Criqui, Silvana Mima, Philippe Menanteau, Alban Kitous
}

\section{To cite this version:}

Patrick Criqui, Silvana Mima, Philippe Menanteau, Alban Kitous. Mitigation strategies and energy technology learning: an assessment with the POLES model. Technological Forecasting and Social Change, 2015, 90, pp.119-136. 10.1016/j.techfore.2014.05.005 . halshs-00999280

\section{HAL Id: halshs-00999280 \\ https://shs.hal.science/halshs-00999280}

Submitted on 4 Jun 2014

HAL is a multi-disciplinary open access archive for the deposit and dissemination of scientific research documents, whether they are published or not. The documents may come from teaching and research institutions in France or abroad, or from public or private research centers.
L'archive ouverte pluridisciplinaire HAL, est destinée au dépôt et à la diffusion de documents scientifiques de niveau recherche, publiés ou non, émanant des établissements d'enseignement et de recherche français ou étrangers, des laboratoires publics ou privés. 


\title{
ÉCONOMIE DU DÉVELOPPEMENT DURABLE ET DE L'ÉNERGIE
}

\section{Mitigation strategies and energy technology learning: an assessment with the POLES model}

\author{
Patrick Criqui \\ Silvana Mima \\ Philippe Menanteau \\ Alban Kitous
}

April 2014

Cahier de recherche EDDEN n 5/2014 



\title{
Mitigation strategies and energy technology learning: an assessment with the POLES model
}

\author{
P. Criqui ${ }^{\mathrm{a}}$, S.Mima ${ }^{\mathrm{a}}$, P. Menanteau ${ }^{\mathrm{a}}$, A.Kitous ${ }^{\mathrm{b}}$, \\ ${ }^{a}$ CNRS, PACTE, EDDEN, F-38000 Grenoble, France \\ ${ }^{\mathrm{b}}$ European Commission (JRC IPTS Sevilla)
}

April 2014

\section{Abstract}

This paper explores various dimensions of the learning process for low-carbon technologies under different mitigation scenarios. It uses the POLES model, which addresses learning as an endogenous phenomenon with learning curves, and a set of scenarios developed as part of the AMPERE project. It represents an analytical effort to understand the learning patterns of energy technologies in various contexts and tries to disentangle the different dimensions of the relation between these patterns and the deployment process. One result is, surprisingly, that apparent learning may be slower in mitigation scenarios with accelerated technology deployment when using two-factor learning curves. Second, the R\&D analysis clearly shows that reductions in R\&D budgets have significant impacts on long term technology costs. Third, solar technology which is more constrained by floor costs in the model, benefits more from major technological breakthroughs than wind energy. Finally, ambitious stabilization targets can be met with limited cost increases in the electricity sector thanks to the impact of learning effects on the improvement in technology costs and performances.

Keywords: Technological change, technology modelling, path dependency, learning by doing, learning by searching, mitigation scenarios, emission constraints

\footnotetext{
* Corresponding author: Dr. Silvana MIMA

E-mail addresses: Patrick.Criqui@upmf-grenoble.fr, Silvana.Mima@upmf-grenoble.fr , Philippe.Menanteau@upmf-grenoble.fr, Alban-Gabriel.KITOUS@ec.europa.eu ,
} 


\section{Introduction}

The process of technological change is identified in the literature as a highly complex one, which involves multiple stages and categories of actors (researchers, developers, technicians, device producers, users, policy makers, etc.) [1, 2]. However in any modelling exercise associated with the use of Integrated Assessment Models for the analysis of greenhouse-gas mitigation strategies, simplifications must be made. In this perspective of applied modelling exercises, we have predominantly focused on two fundamental mechanisms by which technologies evolve. They are typically referred to as "learning-by-doing" [3] and "learning-by-searching" [4]. This reflects the fact that, barring approaches that consider technological change as purely exogenous, one must consider that both the proper deployment of a given technology and the R\&D effort dedicated to this technology have a dynamic impact on costs and performance: in the process of technology improvement over time, both doing and searching matter. These two aspects of the learning process have been integrated through the development, for modelling purposes, of Two-Factor Learning Curves [4]. They have been increasingly introduced into technology assessments [5, 6], and energy and Integrated Assessment Models as a means of representing endogenous technical change [7]. The adoption of Two-Factor Learning Curves (TFLC) in energy system modelling has been an important development. It is however still debated as it introduces new uncertainties, raises data problems and fails to reflect important variables such as efficiency of research, network effects, spillovers, etc. [812]. Moreover, recent studies point out the impact of other factors than pure learning and research activities on cost reductions, commodity prices or scale effects, for example [13]. There is a clear need for continuous research on these topics [14]. Still, the TFLC may be relevant as it provides some insights into the influence of R\&D budgets, a major variable for public policy.

As it focuses on an explicit representation of the energy system and its key technologies, the POLES model was one of the first models to implement Two-Factor Learning Curves (TFLC) [4, 7]. The technology time-series database associated with the POLES model - the TECHPOL database - has 
benefitted from extensive research to develop both learning by doing and learning by searching for technologies in key sectors (power and hydrogen production, transport, energy-intensive industries, building), gathering information from the literature and energy experts throughout the EU. The model thus provides insights into the technological dimension of long-term energy-system transitions, subject to various conditions dependent on climate policies, energy and carbon prices, and technology performance trajectories or technology availability.

Many low-carbon technologies, particularly renewables, are relatively new and are thus characterized by considerable potential for learning. Several cross-cutting papers presenting an overview of this special issue address the topic of deploying low-carbon technologies and transforming the energy system in the framework of AMPERE scenarios [8, 9]. In this paper we analyze results from simulations carried out with the POLES model in this framework, in order to explore the relationships between the learning rates for low-carbon technologies and various mitigation pathways. AMPERE scenarios have two dimensions: a technological dimension with various technology portfolios and assumptions about technological change; and a climate-policy dimension (GHG targets). To reduce the complexity of the analysis we have chosen to focus on nine scenarios, out of 41 , as detailed in Table 1.

Table 1: Name and description of the scenarios used in the analysis

\begin{tabular}{|l|l|}
\hline Scenario name & Scenario Description \\
\hline Base-FullTech-OPT & Baseline with full technology portfolio and no short term target \\
450-FullTech-OPT & $450 \mathrm{ppm}$ with full technology portfolio and no short term target \\
Base-LimSW-OPT & Baseline with constrained solar and wind power and no short term target \\
450-LimSW-OPT & $450 \mathrm{ppm}$ with constrained solar and wind power and no short term target \\
450-LowEI-OPT & $450 \mathrm{ppm}$ with low energy intensity and no short term target \\
450-NucOff-OPT & $450 \mathrm{ppm}$ with nuclear phase-out and no short term target \\
450-LimBio-OPT & $450 \mathrm{ppm}$ with constrained bioenergy and no short term target \\
450-FullTech-HST & $450 \mathrm{ppm}$ with full technology portfolio and high short term target \\
450-FullTech-LST & $450 \mathrm{ppm}$ with full technology portfolio and low short term target \\
\hline
\end{tabular}

Note : For a more detailed description of these scenarios see Riahi et al. [15] 
In the paper we address important issues related to the relationship between technological learning of new energy technologies and climate policies: how do climate policies impact learning in wind and solar technologies? How do delays in policy implementation impact learning and, thus on the cost of technologies? What do accelerated or reduced learning rates imply for the long-term deployment of low-carbon technologies in various scenarios?

Section two provides some background on learning rates and detailed explanation of how TFLCs are implemented in the POLES model. In section three, we analyse the impact of climate policies on learning, based on a comparison between the Base-FullTech-OPT and 450-FullTech-OPT AMPERE scenarios, and the influence of delayed action scenarios (450-FullTech-HST, LST, and OPT) on technical change. Section four focuses only on the scenarios in which factors exogenous to the wind and solar industry impact the deployment of wind and solar energy, like LowEl where intensity is low or other technologies (NucOff, and LimBio) are limited. Section five focuses on the sensitivity of results to changes in TFLC parameters, including sensitivities with different elasticities, technology floor-costs, and assumptions about cumulative R\&D. The impacts of learning on mitigation costs and LCOE are examined in the sixth section. Finally, section seven provides a summary of the findings and conclusions for further research.

\section{Observing and modeling the learning process}

\subsection{The learning process in an historical perspective}

The most common representation of the learning process has been the single factor learning curve with a log-log diagram usually representing the relation between the investment costs of new technologies and cumulative capacity, as a proxy for total production of the corresponding equipment. This relation has been abundantly documented for various types of industries and devices, but the energy sector has certainly been a major application domain [17-21]. This type of 
development, whether in retrospective analyses or in forecasting exercises, has been of major importance in most assessments of the future role of new technologies in GHG mitigation scenarios.

When looking at past data, over what is now a relatively long period, and for some key technologies such as wind or photovoltaic power systems, the following should be borne in mind: learning curves are indeed curves ... not straight lines. Using data from the TECHPOL database, past learning rates have been calculated for four different renewable energy technologies (on-shore wind power, offshore wind power, photovoltaics and concentrated solar power) on the basis of historic cumulative capacities and investment costs for the period 1980-2010 (Figure 1). The fact that there is no strictly linear relation between investment costs and cumulative capacities over a long period clearly indicates that other factors, such as public policies, market conditions, industrial competition and of course R\&D activities, do have an impact on technological trajectories [13,22-25].


Figure 1: Historical learning rates for new energy technologies

The 1980-2010 period can be described as a period of contrasted evolution of new energy technologies, with an initial, 20-year phase of rapid learning and a second phase, after 2000 , of a marked slowdown in cost reduction with even in some cases a reverse trend in investment costs. This can be explained in particular by the increase in the price of many materials used in new energy technologies and also by saturation in energy-equipment production capacities [26]. As a result, the observed learning rates are very different depending on whether they are calculated using data from the initial period $1980-2000$ or from 1980 to 2010 . The whole period, which includes intervals of 
price increases leads to relatively low learning rates, while the initial period of steadily decreasing prices is characterized by much higher learning rates. We will use these contrasted values in the following sections as a reasonable range for the uncertainty on future learning rates, to be compared with the endogenous results of the model.

\subsection{Modelling the learning of energy technologies with a Two Factor Learning Curve}

The POLES model provides consistent images of the future world-energy system, with details at a national level and full trajectories for the $21^{\text {st }}$ century, under exogenous economic growth scenarios. It has been extensively used for the economic assessment of international climate and energy policies $[21,22]$. As a partial equilibrium simulation model, it places special emphasis on the role of technology improvement via innovation and dissemination processes. Explicit representation of technologies includes: 32 power generation technologies, 14 hydrogen production technologies, six types of vehicle in the transport sector and three building types. The model simulates non-linear technology trajectories with path-dependency and lock-in/lock-out effects by combining permanent inter-technology competition and cumulative effects.

The model also provides significant detail both for the energy-consuming sectors (residential, transport, industry) and for decision-making processes in the main processing activities. The microeconomic rationale supporting the adoption of low-carbon technologies can thus be represented. They are explicitly described for power generation (fossil with or without carbon capture and sequestration (CCS), nuclear, hydro, biomass and various renewables), passenger and goods transport (conventional, electric, plug-in hybrid and fuel-cell vehicles), buildings (standard, low-energy and very low-energy) and implicitly for other sectors (fuel switching triggered by relative energy prices, mimicking technological change). 
This sectoral resolution also makes it possible to capture sector-specific constraints affecting the dissemination of technical change, such as inertia on the renewal of end-use equipment, the pace of learning processes, technical asymptotes limiting fuel switching and energy efficiency, socio-political obstacles for nuclear power, and land-use competition for bioenergy resources. The cost dynamic is simulated as a function of cumulative deployment and R\&D investments via two-factor learning curves [4]. Total overnight capital costs are decreasing proportionally to cumulative capacities (learning by doing - LbD) and due to increases in cumulative spending on energy R\&D (learning by searching - LbS). The cumulative capacities for each technology are used as a proxy for the accumulation of experience which impacts the specific investment cost of a given technology, while cumulative public and business $R \& D$ are considered as a proxy variable for the accumulative stock of scientific and technological knowledge gained from basic research in technology. Although the econometric evidence is still limited [4], a large amount of literature on the effect of R\&D on technological change suggests the following formulation [29].

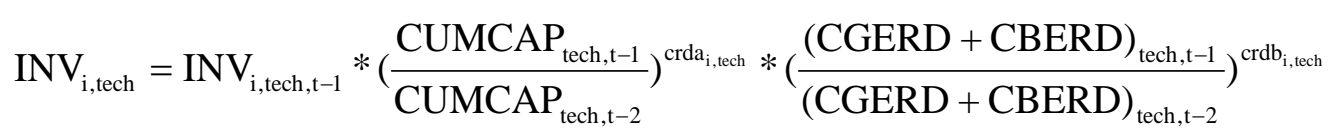

with:

- INVi,tech, INVi,tech,t-1 investment costs of the technology tech (in $\$ / \mathrm{kW}$ ) in the year $\mathrm{t}$ and $\mathrm{t}$ 1 for the country $i$

- CUMCAP, cumulative capacity for the technology tech

- CGERD, cumulative government R\&D and CBERD, cumulative business R\&D for the technology tech

- crdai,tech and crdbi,tech, learning indices defining the speed of learning, derived from the following equations (eq. 2 and eq. 3).

In the POLES model, changes have been made to the usual learning curves to ensure that the cost of a technology will not go down to unrealistically low levels in the very long term. For this purpose, floor-costs corresponding to the lowest attainable cost and variable elasticities (of CRDA and CRDB) have been introduced. As a consequence, in the model the elasticity of learning by doing or learning 
by searching varies with the maturity of the technology; the closer the investment cost comes to the floor cost, the more elasticity decreases until a certain cost threshold is reached, after which elasticity remains null. As a consequence, technological learning gradually decreases when the technology reaches the maturity stage and may even come to a halt for very high deployment and experience levels.

$$
\begin{aligned}
& \mathrm{crda}_{i, \text { tech }}=\mathrm{ECO}_{\text {tech }} * \exp \left(\mathrm{CRDO} 0_{\text {tech }} * \frac{\text { floor }_{i, \text { tech }}}{\text { floor }_{i, \text { tech }}-\operatorname{lnv} v_{i, \text { tech }}}\right) \\
& \mathrm{crdb}_{\mathrm{i}, \text { tech }}=\mathrm{ERDO}_{\text {tech }} * \exp \left(\mathrm{CRD} 0_{\text {tech }} * \frac{\text { floor }_{\text {tech }}}{\text { floor }_{\text {tech }}-\operatorname{lnv} \mathrm{vi}_{\mathrm{i} \text { tech }}}\right)
\end{aligned}
$$

Where:

- "INVi,tech" is the investment cost for technology tech in country $i$

- "floortech" represents the minimum attainable capital cost for technology tech,

- CRDO controls the speed of evolution of elasticities with the distance to the floor cost: a lower value means slower change, as shown on Figure 2. The value used in POLES is 0.1, implying slow evolution until the investment cost gets close to the floor ${ }^{1}$.

- "ECOtech" is the coefficient that sets initial learning by doing elasticity when the technology is immature and the investment cost is high compared to the floor cost - initial LbD elasticity is therefore equal to: [ECO * $\exp (-\mathrm{CRDO})]$. ECO varies from -0.08 for wind offshore to -0.22 for solar PV (see Table 2).

- "ERDOtech" is the coefficient that sets initial learning by searching elasticity when the technology is immature and the investment cost is high compared to the floor cost - initial LbD elasticity is therefore equal to: [ECO * exp(-CRD0)]. ERDO varies from -0.09 for wind offshore to -0.5 for solar photovoltaic (see Table 2).

\footnotetext{
${ }^{1}$ Note: when Inv >> floor, then Inv / (floor - Inv) -1, hence the $(-1)$ appearing in the equation of the initial elasticity.
} 


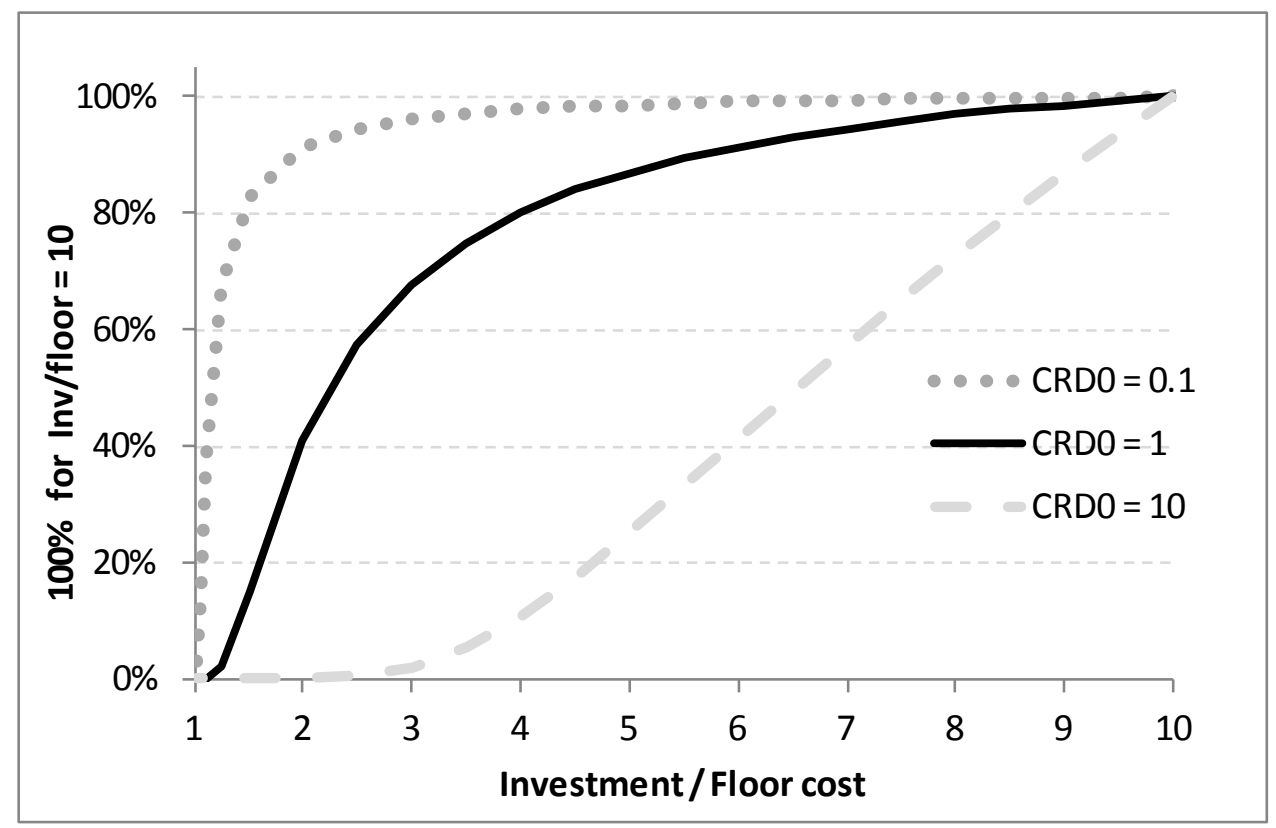

Figure 2: Influence of the evolution factor (CRD0) on the elasticities with the distance to the floor cost

Note: the graph represents the evolution of $\exp (C R D O *$ Inv / (floor - Inv $))$, normalized for Inv / floor $=10$

Table 2 below shows the values of the various parameters used for the FullTech scenario, which corresponds to standard POLES settings. The values have been calibrated using various information sources: TECHPOL database for technology cost (past, current and future - considered to be consistent with a baseline deployment of the technologies), historical technology capacities (IEA / Enerdata) and projected evolution of capacities from a POLES Baseline scenario.

Table 2: Learning curves parameters used by default in POLES (FullTech scenarios)

\begin{tabular}{|c|c|c|c|c|c|c|}
\hline & \multirow{2}{*}{$\begin{array}{l}\text { Floor cost } \\
(\$ 2005 / \mathrm{kW}) \\
\end{array}$} & \multirow{2}{*}{\begin{tabular}{|c|} 
Evolution \\
factor with \\
distance to \\
CRDO \\
\end{tabular}} & \multicolumn{2}{|c|}{ Elasticity to cumulative capacity } & \multicolumn{2}{|c|}{ Elasticity to R\&D } \\
\hline & & & ECO & \begin{tabular}{|c|} 
Initial elasticity \\
(Inv $\gg$ floor $)$ \\
$E C O * \exp (C R D O *(-1))$
\end{tabular} & ERDO & $\begin{array}{c}\text { Initial elasticity } \\
\text { (Inv } \gg \text { floor }) \\
\text { ERDO * } \exp (C R D O *(-1))\end{array}$ \\
\hline Wind on shore & 500 & 0.1 & -0.16 & -0.14 & -0.25 & -0.23 \\
\hline Wind off shore & 700 & 0.1 & -0.08 & -0.07 & -0.09 & -0.08 \\
\hline PV & 1100 & 0.1 & -0.22 & -0.20 & -0.50 & -0.45 \\
\hline CSP & 1100 & 0.1 & -0.15 & -0.14 & -0.30 & -0.27 \\
\hline
\end{tabular}

Calibration of the three parameters takes into account past trends for the relevant technologies or similar ones, and exogenous expert assumptions for expected future performance. The learning ratio 
$\mathrm{LbD}$ is the rate at which the investment cost declines each time the cumulative capacity doubles, whereas LbS is the rate at which the investment cost declines each time the knowledge stock doubles. The relation between $\mathrm{rda}_{\mathrm{i}}, \mathrm{rdb}_{\mathrm{i}}, \mathrm{LbD}$ and $\mathrm{LbS}$ can be expressed as follows:

$$
\begin{aligned}
& \mathrm{LbD}_{\text {tech }}=1-2^{- \text {-rdatech }} \\
& \mathrm{LbS}_{\text {tech }}=1-2^{- \text {crdbtech }}
\end{aligned}
$$

As a consequence of evolving crda and $c r d b, L b D$ and $L b S$ also evolve over time with the distance to the floor cost.

\subsection{The relative roles of $\mathrm{LbS}$ and $\mathrm{LbD}$}

One should note that when represented in a two-dimensional space, the process of learning with two factors may display apparently counter-intuitive patterns. On a single-factor learning curve, when the cumulative capacity of a given technology is accelerated, due to changing market conditions or to public incentives, the cost decrease is quicker but the relation between costs and cumulative capacities remains linear (on a log-log scale). Conversely, with a two-factor learning curve, when the cumulative capacity growth is accelerated, then the apparent learning factor decreases.

Figure 3 represents the learning process using a two-factor learning curve with two contrasted assumptions about cumulative capacity growth (baseline - dark grey curve - versus accelerated dissemination - light grey curve). The final cumulative capacity is identical (by construction) for both curves but it is reached in 2050 in one case (baseline) and in 2035 in the other (accelerated dissemination). As the cumulative R\&D is lower in 2035 compared to 2050 ( $R \& D$ is assumed to grow as a function of time), the learning by searching factor has less impact on the investment-cost decrease. The apparent learning factor expressed as a function of cumulative capacity is consequently lower in the accelerated-deployment scenario. This counter-intuitive pattern will be observed below in the results provided by the POLES model. 


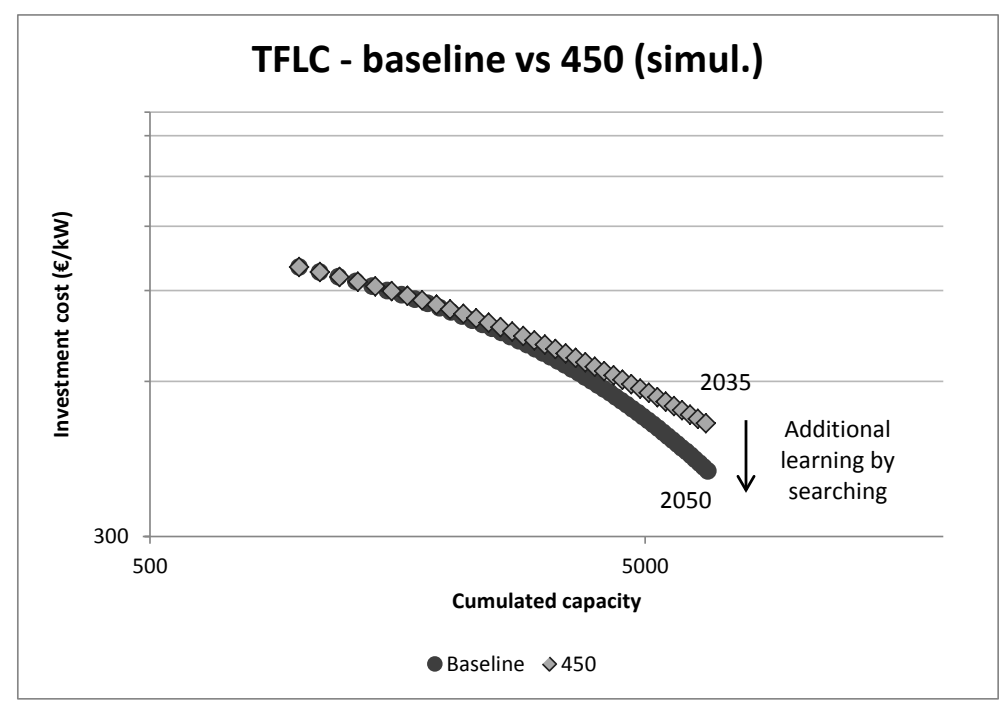

Figure 3: Impact of the LbS factor on the shape of the learning curve

The effects of the experience and knowledge factors on reducing investment costs are highly sensitive to parameters describing the pace of technology improvement as a function of cumulative capacities and cumulative R\&D expenditure. In the following graphs, we explore the relative contribution of LbD (assuming zero LbS elasticity) and LbS (assuming zero LbD elasticity). The impacts of both are compared to the effects of the baseline TFLC rates on reducing investment costs for wind and solar technologies using the 450-FullTech-OPT AMPERE scenario. 


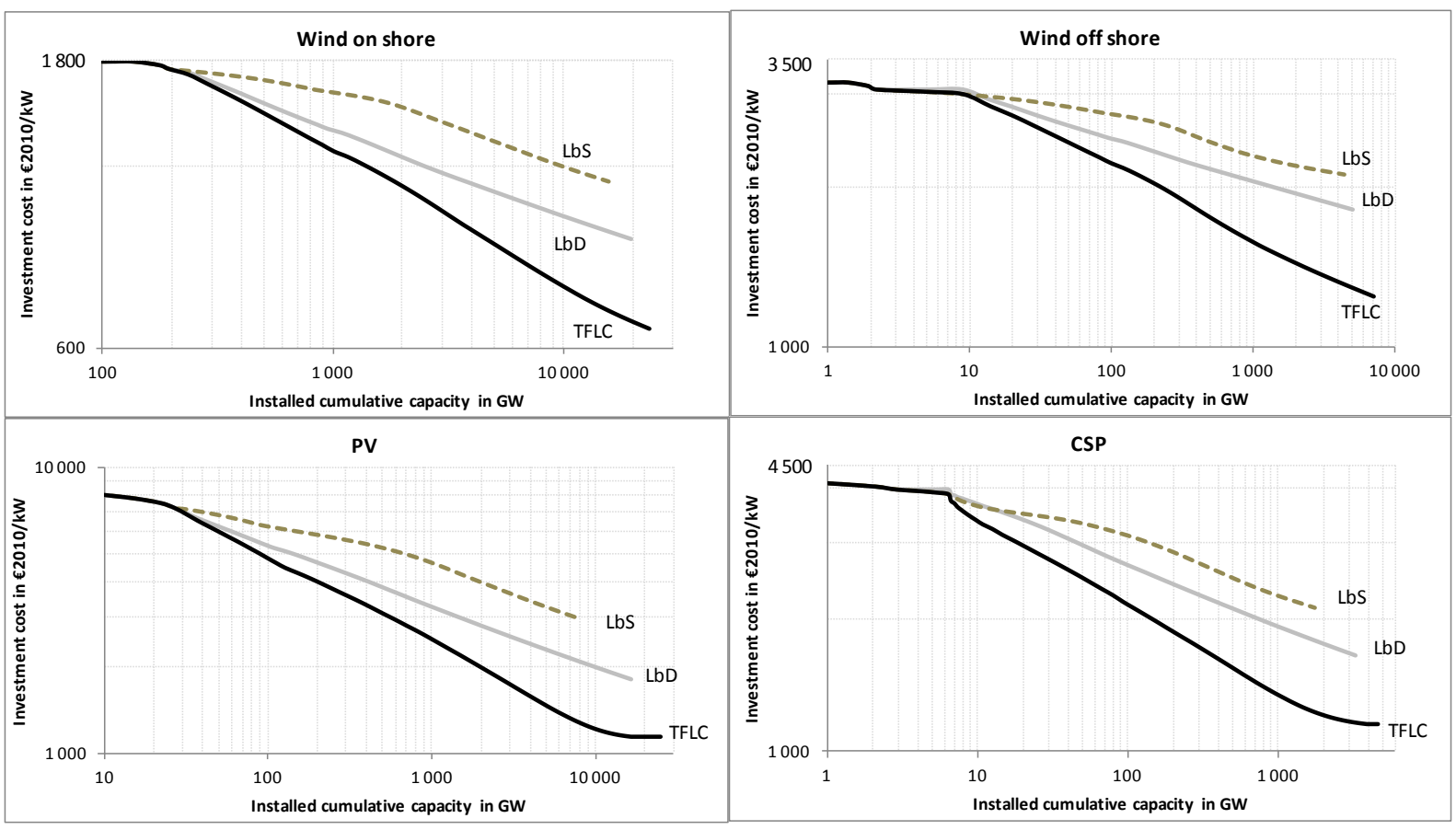

Figure 4: The separate and cumulative effects of LbD and LbS on reducing investment costs for wind and solar technologies in the 450-FullTech-OPT

As expected neutralizing one or other learning factor results in a sharp slowdown in the reduction of investment costs for the four technologies and accordingly in much lower cumulative installed capacity. Both factors contribute to learning but, with the standard-parameter value used in the TFLCs, deployment and cost reductions are smaller on the learning curves using LbS alone compared to the curves with LbD alone. For PV technology, for which the impact is greatest, the cumulative capacity is divided by three and the investment cost is three times higher compared to the baseline case with both LbD and LbS. This behaviour corresponds to the observed evolution of emerging technologies which benefit from both LbD and LbS, while learning by searching has less influence over mature technologies. As far as emerging technologies are concerned, LbD and LbS both influence the progression of performance while learning by searching has less influence over mature technologies. 


\subsection{The energy $R \& D$ database issue}

The TFLC approach has been used in several modelling studies (such as SAPIENT [30], CASCADEMINTS [31], MENGHTECH [32]). The main difficulty with TFLCS is gathering suitable datasets to estimate such learning models, especially in terms of cumulative R\&D, the knowledge stock, and dealing with brand new technologies. There is also a need for more research into the underlying effects and processes that learning curves tend to capture. This is particularly important when considering the potential impacts of learning in terms of policy recommendations, which may be as significant as the decision to delay mitigation strategies or on the other hand to engage intensive action early on [33]. Despite these limitations, learning by doing and by searching clearly does impact the cost and performance of technology development. Incorporating such dynamics in energy models thus significantly improves the realism of the description of long-term technology dynamics.

Regarding the construction of the database of (private and public) R\&D expenditure in the POLES model, the Government Energy R\&D database has been updated from Sapientia, Cascade Mints and Mengtech DB with the latest available IEA data. GERD-DB intends to provide a comprehensive view of energy R\&D, in spite of the uncertainties attached to total spending and categories. This has entailed the survey of a wide variety of publications, Community Research \& Development Information Service (Cordis) and US Department of Energy (DOE) energy programme databases.

Sources for private $R \& D$ data in particular have proved rather scant. This type of data is mostly considered of strategic value and hence not readily released for public use. It has been necessary to use indirect methods to obtain simply reasonable estimates. These include gross R\&D expenditure by specialized companies which are key players in technology development in the relevant domains, patent application data for apportioning such expenditure to specific technologies, and other innovative methodology involving indirect methods depending on relevant indices. 
The construction of the R\&D expenditure database has been a challenging and innovative task. Considerable difficulties have been encountered especially due (rather surprisingly) to the scarcity and unreliability of historical information on technology costs. Two methodological difficulties arise when assessing this variable: the first relates to estimating the initial amount of cumulative research; the second to the need to take into account a "scrapping rate" for outdated knowledge.

As far as initial cumulative research is concerned, we have assumed in this analysis that R\&D expenses have increased linearly between the starting year and the first year of statistical record. For lack of empirical data for the energy technologies and to simplify analysis, the "scrapping rate of knowledge" has been neglected. For the future it was necessary to elaborate an outlook for R\&D efforts dedicated to the various technological options. This outlook was based on past trends, recent changes in emphasis and foresight analysis based on judgement; it is not the result of rigorous modelling logic. On the other hand, effort were made to maintain some consistency and allow for a clear picture of the direction of future renewable R\&D.

The general shape of the outlook is based on the neutral assumption that both Government Energyrelated R\&D (GERD) and Business Energy-related R\&D (BERD) will grow proportionally with GDP, between 2010 and 2050. This assumption leads to substantial growth in R\&D on renewable technologies for the next 40 years, a constant level being maintained after 2050, with broadly declining energy R\&D shares in global GDP.

\section{The impact of climate policies on learning}

In the AMPERE project, 41 scenarios were simulated with the POLES model, in compliance with the project's WP2 protocol [15]. These scenarios correspond to the combination of baseline cases and contrasted climate policies to stabilize CO2 concentrations at 450 or 550 ppm CO2e in 2100, with either high or low targets in the medium term (2030), and finally with various assumptions on the availability of abatement technologies. A detailed description of the scenarios is provided in Riahi et 
al. [15]. In this section the main issue is the impact of specific climate policies on the deployment of low-carbon technologies and the resulting effects on learning and cost dynamics.

\subsection{Ambitious versus baseline climate policy scenario}

This section compares a reference scenario with no climate policy to a mitigation scenario with a long-term target of $450 \mathrm{ppm}$ in 2100.

As illustrated by the comparison of two contrasted climate policy scenarios (Base-FullTech-OPT versus 450-FullTech-OPT), a powerful carbon constraint entails major changes in the deployment of renewable technologies with substantial consequences for the power generation mix. The most important impacts of the carbon constraint, compared to a baseline case, are as follows (see Figure 5 below):

- a powerful impetus is given to power production from variable renewables - wind and solar - which together nearly reach a third of total electricity generation in 2050 and half of it in 2100; these sources thus play a key role, but are not sufficient by themselves to achieve full decarbonization of the electricity system;

- the full replacement in 2100 of conventional thermal power plants by a mix of fossil-based plants with CCS and biomass-based generation (biomass increases by a factor of 5 compared to baseline);

- powerful CCS development representing $30 \%$ of total installed capacity in 2050 and $20 \%$ in 2100 when other low-carbon options will have been fully developed;

- similarly, nuclear power is more positively impacted in the medium term (2030-50) than in the very long term, with significantly higher production than in the Baseline in 2100, while all low-carbon options represent $70 \%$ of total production in the 450 CO2e scenario. 
This outlook shows that there is no "silver bullet" or miracle technological option, and that a full portfolio that mobilizes all existing low-carbon options will be needed to meet ambitious climate targets.

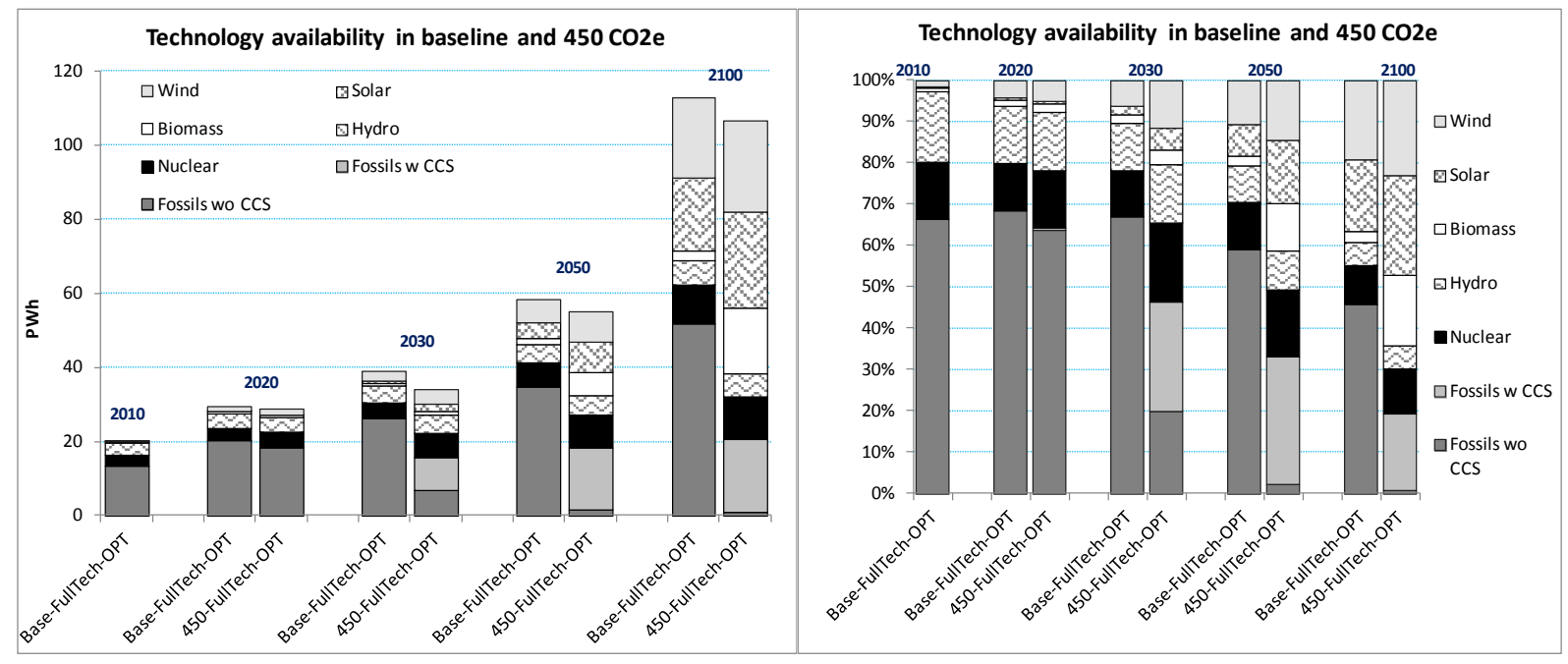

Figure 5: Technology deployment in baseline and 450 co2e scenarios $^{2}$

As mentioned above, the POLES model is well suited to analysing the technological changes induced by ambitious climate policies, since it endogenizes future changes in the costs and performance of new energy technologies which are not yet mature and subject to learning processes. This is particularly the case in the power generation sector, for variable renewable technologies such as wind (on and off-shore) and solar (photovoltaics or concentrated solar power).

Base-FullTech-OPT and 450-FullTech-OPT are also used to compare the learning behaviour of these renewable technologies under different assumptions about the stringency of the climate policy. In the following figures (Figure 6), learning curves for wind and solar technologies have been plotted for the two scenarios with similar assumptions about the availability of the technologies.

\footnotetext{
${ }^{2}$ Base-FullTech-OPT - Baseline with full technology portfolio and no short term target; 450-FullTech-OPT - 450 ppm with full technology portfolio and no short term target
} 


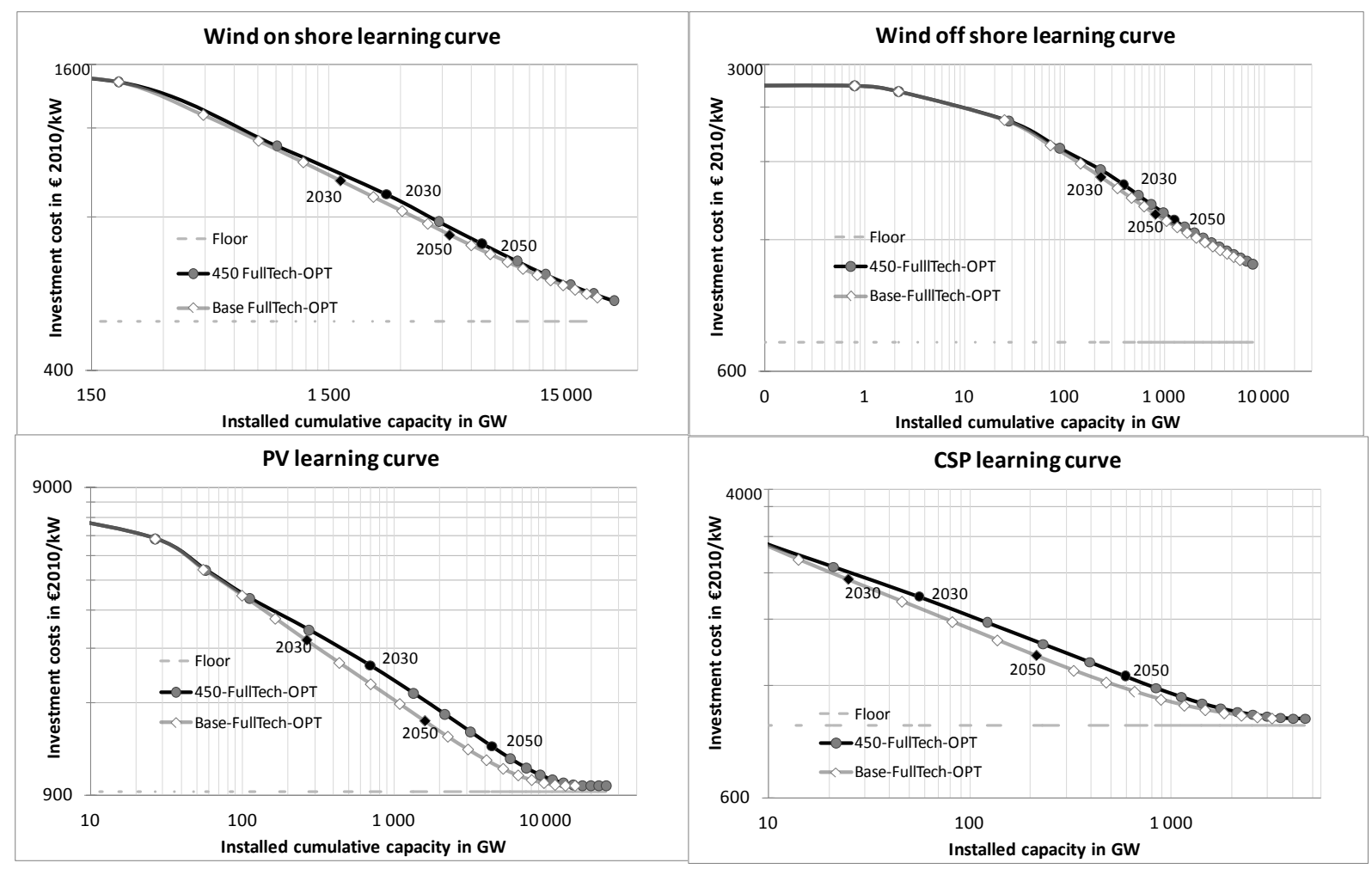

Figure 6: Learning curves of wind onshore (WND), offshore (WNO), photovoltaic (PV), centralized solar power (CSP)- in Base-FullTech-OPT and 450-FullTech-OPT scenarios in Log-Log

The four graphs in Figure 6 display similar features. The introduction of an ambitious climate policy (450-FullTech-OPT) modifies the shape of the learning curve for each technology compared to the baseline scenario (Base-FullTech-OPT). The most noticeable effect is not a surprise: the spread of low-carbon technologies is accelerated by the introduction of a carbon tax, as can be seen on cumulative installed capacities at the right end of the curves. The effect may not be fully visible because of the log-log scales, but by the end of the period, the installed capacity of low-carbon technologies is significantly higher in the $\mathrm{CO} 2$ constrained scenarios: $20 \%$ and $30 \%$ higher for on and off-shore wind, respectively, almost $50 \%$ for CSP and $60 \%$ in the case of PV.

While the deployment is impacted as expected, the ultimate technology costs are surprisingly not much lower in the climate policy scenario compared to the baseline. This is a consequence of the introduction of variable elasticity which slows down learning when the investment cost comes closer to the floor. The similar shape of the curves is also due to the fact that, in the long term, the rate at which cumulative capacity doubles is increasingly close in both scenarios. In the end the 450 scenario 
achieves higher cumulative capacities but the ultimate cost is very close to the one reached in the baseline scenario.

Another important feature of the learning curves is the lower apparent learning factor in the accelerated-deployment scenario. One would expect learning to be faster in a scenario which stimulates the deployment of renewable technologies but Figure 6 shows a lower slope for the 450 scenario, which means a lower apparent learning rate. In the climate policy scenario, introducing a carbon price improves the competitive position of renewable technologies and boosts their dissemination. For a given technology cost, the level of cumulative capacity is therefore much greater in this scenario compared to the baseline because of improved competitiveness. As a consequence, the curve shifts upwards or, more precisely, to the right. Simultaneously, the learning by searching effect is lower in the climate-policy accelerated-deployment scenario because the stock of cumulative R\&D, which increases with time, is smaller for a given cumulative capacity. As a result, there is a shift in the learning curve and the learning rate seems to be lower for the accelerated deployment scenario compared to the baseline.

One partial conclusion at this stage is that the average learning rate (represented by the slope of the learning curve connecting investment cost and cumulative capacity) is not necessarily accelerated (the slope does not decrease) with the implementation of an aggressive climate policy. But learning is accelerated in the sense that a given cumulative installed capacity and a given cost are reached, for low-carbon technologies, in a shorter time with the accelerated-deployment scenario compared to the baseline.

\subsection{Delayed versus early action in climate policy}

One of the goals of the AMPERE project has been to analyse the long-term impacts of different emission targets by 2030 , in order to assess extent to which the future energy system and long-term CO2 abatement costs are dependent on irreversibility stemming from the short-term path. Cross- 
cutting papers in this special issue compare two sets of scenarios which all comply with trajectories consistent with the $450 \mathrm{ppm}^{3}$ target but are differentiated along two 2030 emission levels: a "Low" target with emissions $16 \%$ lower ( $37 \mathrm{GtCO} 2$, called $\mathrm{LST}^{4}$ ) and a "High" 2030 target $\left(44 \mathrm{GtCO}^{5}\right.$, called $\left.\mathrm{HST}^{6}\right)$. Our analysis clearly shows that the timing of decarbonization of the power mix is a key factor in the transition process: earlier action, engaged before 2030, may be more expensive in the short run but produces very significant savings in the decarbonization process over the entire period. In this sub-section we intend to complement this analysis while assessing the impacts of early versus delayed action on the deployment and learning of renewable technologies. The following figure synthesizes the average annual capacity growth rates for different technologies for three periods 2010-30, 2030-50 and 2050-2100 and three 450-FullTech scenarios, OPT, LST and HST.

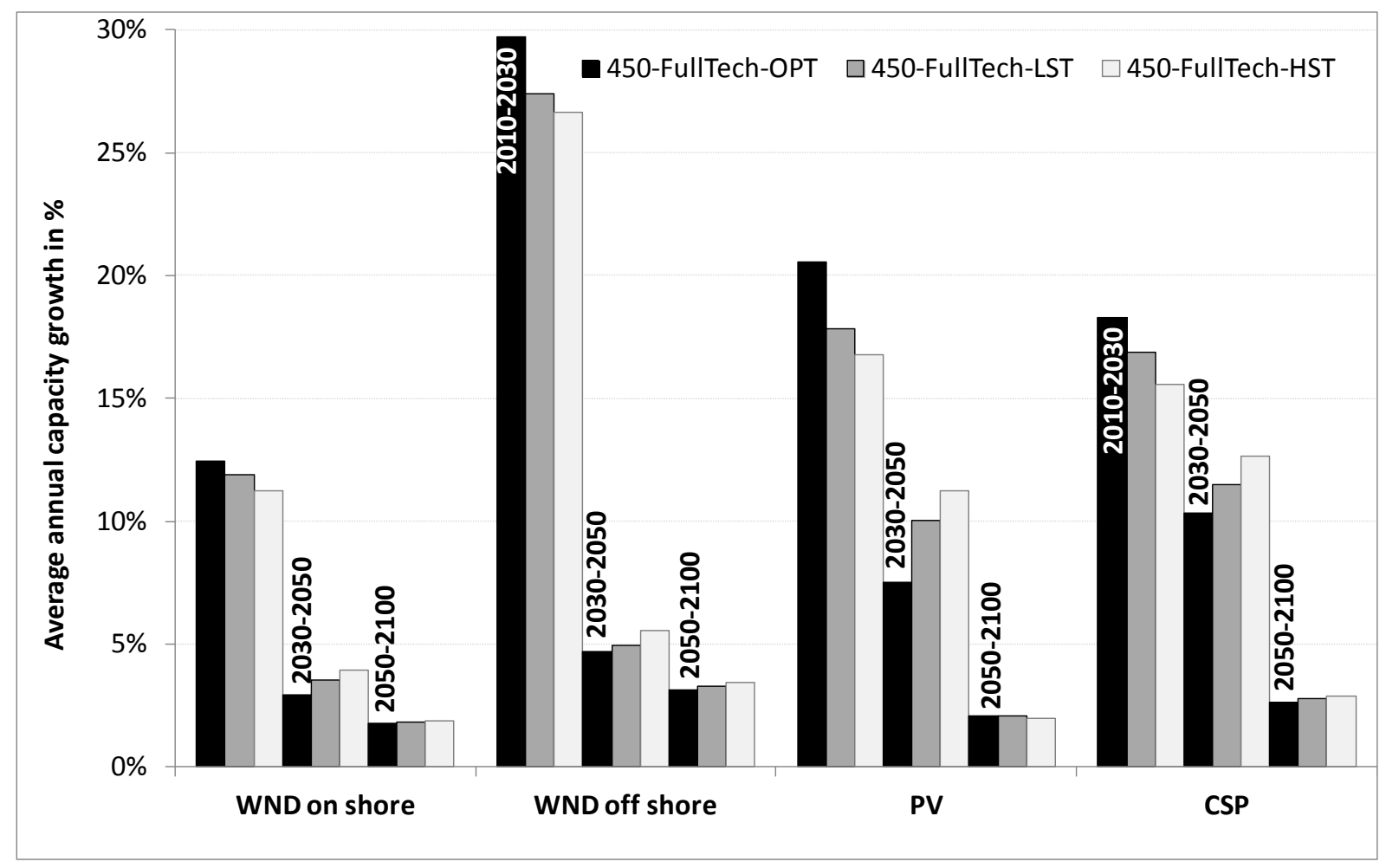

Figure 7: Impact of delayed versus early action on capacity deployment for different technologies

\footnotetext{
${ }^{3}$ Total cumulative $\mathrm{CO} 2$ emissions from fossil fuel combustion and industrial process, over 2000-2100, amount to 1400 GtCO2

${ }^{4}$ LST: Low Short Term

${ }^{5}$ World $2010 \mathrm{CO} 2$ emissions from fossil fuel combustion and process reached $32 \mathrm{GtCO} 2$

${ }^{6}$ HST: High Short Term
} 
Generally, deployment of renewables is slower in the 2010-30 period with less stringent policies, but then accelerates between 2030 and 2050 - assuming the same long-term target - because of the necessity to compensate for the delays in the first period. However, there is a very similar deployment in the 2050-2100 period in all scenarios.

Table 3: Impacts of delayed versus early action on learning rates of different technologies in 450-FullTech-OPT, HST and LST for three periods, 2010-2030, 2050-2030 and 2050-2100

\begin{tabular}{|c|c|c|c|c|}
\hline & \multirow{2}{*}{$\begin{array}{l}\text { Historical } \\
1980-2010\end{array}$} & 450-FullTech-OPT & 450-FullTech-LST & 450-FullTech-HST \\
\hline & & \multicolumn{3}{|c|}{$2010-2030$} \\
\hline WND on shore & $6 \%$ & $10 \%$ & $6.5 \%$ & $6.7 \%$ \\
\hline WND off shore & $3 \%$ & $7 \%$ & $3.7 \%$ & $3.8 \%$ \\
\hline PV & $19 \%$ & $19 \%$ & $15.5 \%$ & $16.6 \%$ \\
\hline \multirow[t]{2}{*}{ CSP } & $0 \%$ & $13 \%$ & $9.1 \%$ & $9.1 \%$ \\
\hline & & \multicolumn{3}{|c|}{$2030-2050$} \\
\hline WND on shore & & $12 \%$ & $13.1 \%$ & $12.7 \%$ \\
\hline WND off shore & & $11 \%$ & $9.3 \%$ & $8.9 \%$ \\
\hline PV & & $0 \%$ & $10.0 \%$ & $9.1 \%$ \\
\hline \multirow[t]{2}{*}{ CSP } & & $6 \%$ & $10.6 \%$ & $10.6 \%$ \\
\hline & & \multicolumn{3}{|c|}{$2050-2100$} \\
\hline WND on shore & & $11.9 \%$ & $15.4 \%$ & $15.0 \%$ \\
\hline WND off shore & & $8.7 \%$ & $8.7 \%$ & $8.1 \%$ \\
\hline PV & & $0.0 \%$ & $3.6 \%$ & $3.6 \%$ \\
\hline CSP & & $2.1 \%$ & $4.1 \%$ & $4.1 \%$ \\
\hline
\end{tabular}

Ex-post learning rates have been calculated for the three periods $2010-30,2030-50$ and $2050-2100$ and are presented in Table 2 for the three scenarios. The first and most important point is that the HST and LST scenarios on the one hand, and the OPT scenario on the other, provide quite different learning curves but the learning curves in HST and LST scenarios are very similar. As a consequence, the differences in learning rates observed between LST and HST may not be as significant as the differences between OPT and LST/HST. The second point is that, in the first period, the learning rate is higher in the OPT scenario with more stringent constraints on CO2 compared to LST/HST. In the following periods, the opposite effect on learning is observed because of the strong additional constraints affecting LST/HST emission trajectories. Another interesting finding is that the learning rate for wind remains similar or accelerates over time whereas for solar, it generally declines with time. This is likely related to the fact that solar approaches the floor-cost much more quickly than wind. 


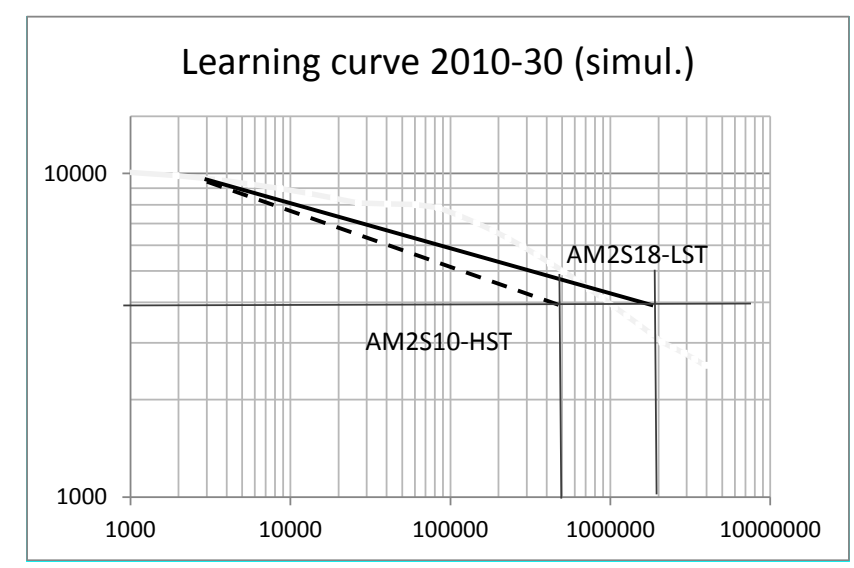

Figure 8: Learning in LST versus HST scenarios

Ultimately it is odd to observe that learning rates in 2010-30 are lower in the LST scenario than in the HST scenario, contrary to what one would expect: indeed a larger development with the same cost corresponds to a lower slope of the learning curve, i.e. learning rate. This is the result of the more favourable competitive conditions created by the higher carbon price in the HST scenario, as explained above (see 3.1). The gap between the two trajectories is very small (the difference in cumulated capacity is $10 \%$ and less than $1 \%$ for the investment cost between LST and HST scenarios in 2030), but the better competitive conditions for renewable technologies in the LST scenario compared to HST increases dissemination for a given investment cost. The learning curve thus shifts to the right and the resulting learning rate is lower despite, or rather due to, the higher carbon constraint (Figure 8).

\section{Impact of the changing competitive environment on learning}

There is little understanding of the changing competition framework through major events such as significant improvements in efficiency, or conversely nuclear setback or constraint bioenergy, impacts on the variable renewable deployment and learning process. The aim of this section is to explore learning impacts associated with these events using three different AMPERE scenarios run with the POLES model:

- High efficiency improvement (450 LowEl-OPT) 
- $\quad$ No nuclear energy (450 NucOff-OPT)

- Bioenergy constraint (450-LimBio-OPT).

Analysis is divided into two components: one on the impact of reduced energy demand (LowEl scenario); and one on the impact of changing competition framework in the NucOff and LimBio scenarios on learning for solar and wind technologies.

\subsection{Reduction of electricity demand: the LowEI scenario}

In the AMPERE scenarios the "Low" energy intensity level represents an ambitious efficiency pathway for the world, corresponding roughly to a $50 \%$ increase of the energy-intensity reduction rate compared to the "Ref" case. The resulting electricity demand levels out to half of the consumption estimated in the 450 FullTech scenario, which indeed translates into a strong reduction in production, significant changes in competition between electricity generation technologies and major transformations in the electricity mix (Figure 9).

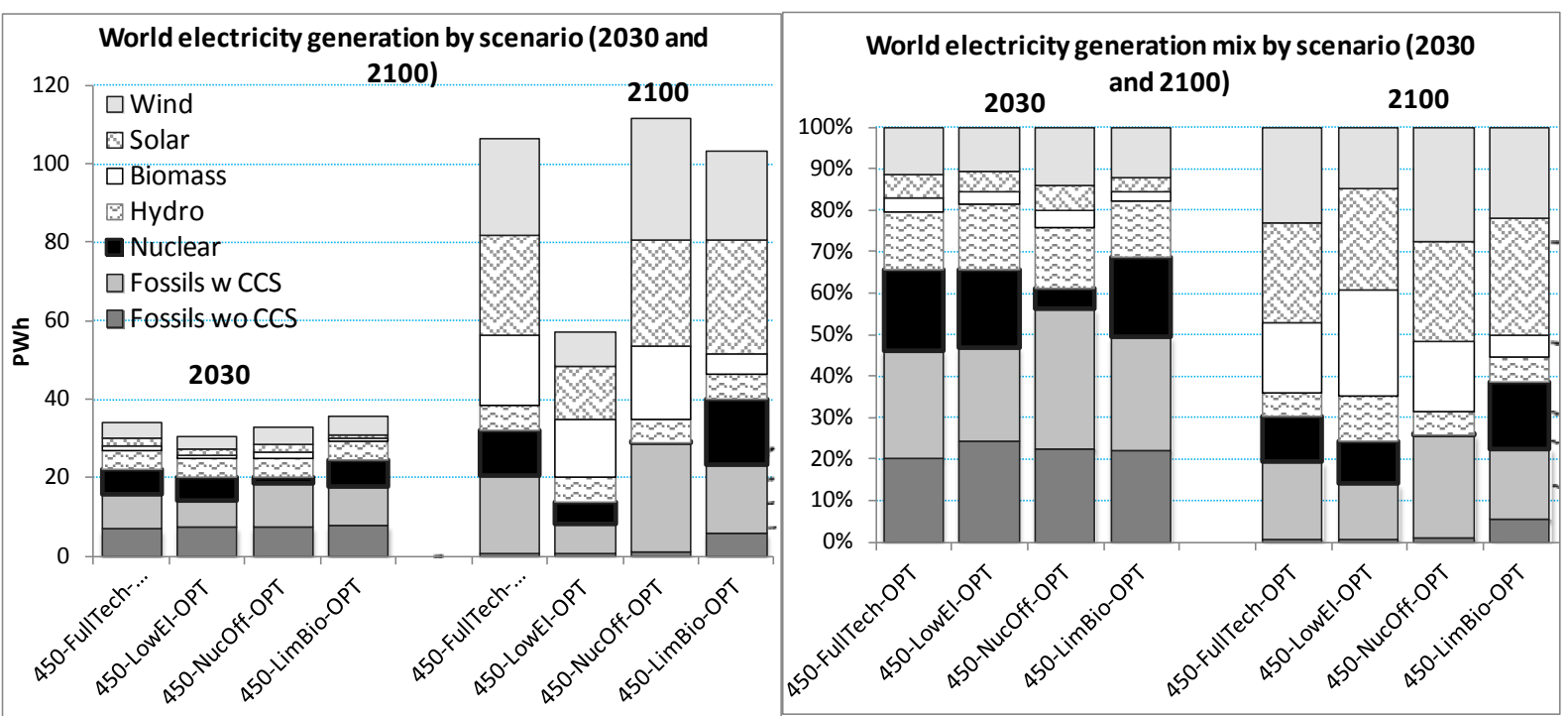

Figure 9: World electricity generation mix by scenario (2030 and 2100)

An important finding in the AMPERE project is the evidence that, compared to 450 FullTech, the 450 LowEI scenario reduces the need for renewable technologies and profoundly changes structural conditions. Solar and wind generation shrink respectively to $54 \%$ and $35 \%$ of their level in the 
FullTech scenario, but the apparent learning rate is also positively affected in this scenario. The impact of contrasted deployment rates on learning has already been described (see Section 2); while accelerated deployment leads to a lower apparent learning rate, reduced cumulative capacities for renewable technologies induce a higher apparent learning in the high-efficiency scenario, because of the stronger impact of the learning-by-searching component (see Table 4).



Figure 10: The consequences of Low energy efficiency on Renewable Learning rates

\subsection{Restrictions on major zero-emission technologies: the NucOff and}

\section{LimBio scenarios}

The AMPERE project has also considered the various types of barrier to technology deployment connected with public acceptance of potential environmental hazards, possibly leading to one or more key technologies for long-term decarbonization becoming unavailable on a large scale. This section describes learning impacts associated with less competition to solar and wind energy due to a 
nuclear setback (NucOff) or less available bioenergy (LimBio). Surprisingly, the changes in the electricity mix in these cases are more limited than in the low energy intensity scenario. Figure 9shows that in NucOff scenario, most of the nuclear capacity is substituted by fossil power plants with CCS. As underlined by Krey and Clark [34], wind and solar are probably too expensive and variable to be full substitutes for nuclear energy. As a consequence, their contribution increases only slightly compared to the 450-FullTech scenario. As this is difficult to see in the log figures, Table 4 indicates that the cumulative capacity of on and off-shore wind increases respectively by $7-14 \%$ and $16-33 \%$ during the period. Due to this learning by doing the investment costs of each technology decreases respectively by $1 \%$ and $2 \%$ by the end of the period. The consequences of a nuclear setback on solar learning profiles are lower due to their limited impact on the increase in installed capacities.

Similar behaviour can be observed in the 450-LimBio-OPT scenario, with a limited increase in the production of solar and wind energy when the contribution of bionergy is constrained, because of the limits built into the model to control the contribution of variable renewables.

Table 4: The consequences of nuclear setback and bioenergy constraint on wind and solar deployment and learning (in terms of changes compared to $450-$ FullTech-OPT)

\begin{tabular}{|c|c|c|c|c|c|c|}
\hline & \multicolumn{2}{|c|}{2030} & \multicolumn{2}{|c|}{2050} & \multicolumn{2}{|c|}{2100} \\
\hline & $\begin{array}{l}\text { Changes of Installed } \\
\text { cumulative capacities }\end{array}$ & $\begin{array}{c}\text { Changes of } \\
\text { investment costs }\end{array}$ & $\begin{array}{l}\text { Changes of Installed } \\
\text { cumulative capacities }\end{array}$ & $\begin{array}{c}\text { Changes of } \\
\text { investment costs }\end{array}$ & $\begin{array}{l}\text { Changes of Installed } \\
\text { cumulative capacities }\end{array}$ & $\begin{array}{c}\text { Changes of } \\
\text { investment costs }\end{array}$ \\
\hline \multicolumn{7}{|l|}{ Wind on shore } \\
\hline 450-NucOff-OPT & $10 \%$ & $-1 \%$ & $7 \%$ & $-1 \%$ & $14 \%$ & $-1 \%$ \\
\hline 450-LimBio-OPT & $-0.2 \%$ & $0 \%$ & $2 \%$ & $-0.2 \%$ & $-15 \%$ & $1 \%$ \\
\hline \multicolumn{7}{|l|}{ Wind offshore } \\
\hline 450-NucOff-OPT & $22 \%$ & $-1 \%$ & $16 \%$ & $-1 \%$ & $33 \%$ & $-2 \%$ \\
\hline 450-LimBio-OPT & $0.0 \%$ & $0 \%$ & $18 \%$ & $-1 \%$ & $30 \%$ & $-2 \%$ \\
\hline \multicolumn{7}{|l|}{ PV } \\
\hline 450-NucOff-OPT & $17 \%$ & $-3 \%$ & $11 \%$ & $-2 \%$ & $3 \%$ & $0 \%$ \\
\hline 450-LimBio-OPT & $6 \%$ & $-1 \%$ & $5 \%$ & $-1 \%$ & $5 \%$ & $0 \%$ \\
\hline \multicolumn{7}{|l|}{ CSP } \\
\hline 450-NucOff-OPT & $17 \%$ & $-2 \%$ & $8 \%$ & $-1 \%$ & $13 \%$ & $0 \%$ \\
\hline 450-LimBio-OPT & $5 \%$ & $-1 \%$ & $11 \%$ & $-1 \%$ & $30 \%$ & $0 \%$ \\
\hline
\end{tabular}

In spite of a profound change of structural conditions, due to the removal of two key competing technologies, there is no evidence of major transformations in the deployment and learning of renewable technologies. The impact on the learning rates is more visible for offshore wind and CSP, probably because the deployment of these emerging technologies is more sensitive to changes in the 
competitive environment (see Figure 6). Nuclear-off and limited biomass scenarios do not noticeably alter the learning curve because they are substituted by CCS more than by wind and solar.

\section{The impact of changing parameters on technological learning}

Section 5 examines what happens when we change assumptions about the elasticities (ERDO and ECO), floor costs (floortech), and cumulative R\&D (CGERD and CBERD).

\subsection{New assumptions about learning rates}

Four AMPERE scenarios - with and without the 450 CO2e emission constraint and with full or limited potential for solar and wind (Base-FullTech-OPT, 450-FullTech-OPT, Base-LimSW-OPT and 450LimSW-OPT) - have been compared to analyse ex-post learning curves as simulated by the model. These scenarios with contrasted features have been chosen according to the diagram in Figure 11.



Figure 11: Scenarios for studying ex-post learning curves

Table 5 compares the learning curve parameters of the LimSW case with the FullTech case. The two cases are based on differentiated cost trajectories: the "LimSW" was calibrated to follow a more conservative cost trajectory provided in the AMPERE project [15]. As a consequence, in LimSW floor costs are higher $(+50 \% /+80 \%)$ and the initial elasticity to cumulative capacity (ECO) is lower $(-20 \% /-$ 
70\%). The initial elasticity to R\&D (ERDO) is derived from these in such a way as to comply with the historical and initial investment cost: by construction it is higher than in the FullTech case.

Table 5: Parameterization of the cost curves in two scenarios: FullTech (standard settings) and LimSW (more conservative on Wind and Solar)

\begin{tabular}{|c|c|c|c|}
\hline & \begin{tabular}{|c|} 
Floor cost \\
$(\$ 2005 / \mathrm{kW})$
\end{tabular} & $\begin{array}{l}\text { Elasticity to cum. capacity } \\
\text { ECO }\end{array}$ & $\begin{array}{c}\text { Elasticity to R\&D } \\
\text { ERDO }\end{array}$ \\
\hline \multicolumn{4}{|l|}{ Wind on shore } \\
\hline LimSW & 800 & -0.05 & -0.33 \\
\hline$\%$ diff with FullTech & $60 \%$ & $-70 \%$ & $30 \%$ \\
\hline \multicolumn{4}{|l|}{ Wind off shore } \\
\hline LimSW & 1050 & -0.04 & -0.14 \\
\hline$\%$ diff with FullTech & $50 \%$ & $-50 \%$ & $50 \%$ \\
\hline \multicolumn{4}{|l|}{ PV } \\
\hline LimSW & 2000 & -0.09 & -1.50 \\
\hline$\%$ diff with FullTech & $80 \%$ & $-60 \%$ & $200 \%$ \\
\hline \multicolumn{4}{|l|}{ CSP } \\
\hline LimsW & 1650 & -0.13 & -0.55 \\
\hline$\%$ diff with FullTech & $50 \%$ & $-20 \%$ & $80 \%$ \\
\hline
\end{tabular}

The cumulative installed capacity and investment costs simulated with the model are compared to past observed learning in the Figure 12 for each technology in the four different scenarios. Most of the technologies present a slowdown of learning by the end of the period but this is more apparent for photovoltaic (PV) and concentrated solar power (CSP). The slowdown in learning for PV which occurs by the end of the period can be explained by the fact that this technology reaches the floorcost mentioned earlier. This prevents the investment cost from falling below a set limit, identified as a kind of physical limit. It represents the intrinsic or theoretical constraints to a reduction in the cost of the different components of one technology. 


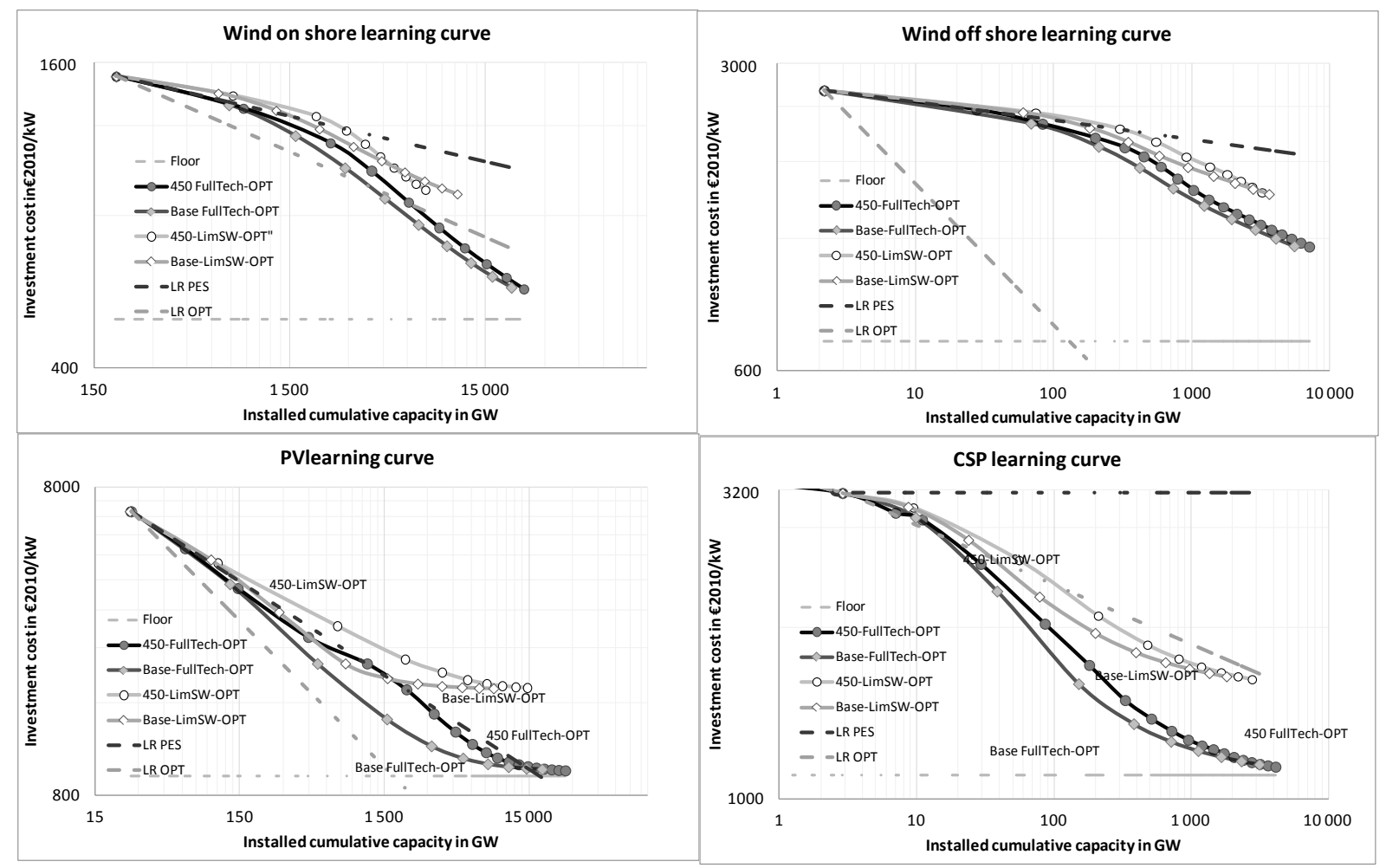

Note: $L R-P E S$ - pessimistic learning rates and LR-OPT - optimistic learning rates.

Figure 12: Technological changes induced by the scenario-IRE learning rates

As a benchmark, we also introduced in Figure 12 two straight lines representing the high and low learning rates historically observed in the past (for the 1980-2000 and 1980-2010 periods), referred to as optimistic (OPT) or pessimistic (PES), as mentioned above in sub-section 2.1. For onshore wind, for example, the simulated learning rates are higher than those observed between 1980 and 2010 and quite close to those observed in 1980-2000; this means that the fast learning process observed in the period of emergence carries on after 2000. For CSP, in the advanced scenarios, the learning rates are even higher than the "optimistic" one, but full development of the technology is also more recent and less consolidated compared to the other technologies, resulting in highly uncertain learning rates.

The different scenarios provide two contrasted learning profiles, although with similar shapes: the FullTech scenarios on the one hand and the LimSW on the other. The results observed with the first 
family (FullTech) have already been discussed above. The second family (LimSW) is based on conservative assumptions about dissemination and learning for wind and solar technologies:

- Higher floor cost

- Lower learning rate

- Constraints on maximum dissemination (as a percentage of electricity production)

This provides a clearly different profile with a resulting cumulative capacity which is much lower compared to the "FullTech" scenarios. As the learning rates are lower by construction, the resulting investment costs are less favourable in the end for scenarios with limited dissemination. As stated above, the apparent learning factor is higher in the no-policy situation because of the effects of lower cumulative R\&D in the 450 scenario.

One outcome of these cases is that a slower learning process and constrained dissemination of technology may prevent renewable energy technologies from reaching their ultimate performance level and thus from playing a key role in the production mix. Even if ambitious climate policies are implemented, the constraints on dissemination and learning are not compensated for by the introduction of a high carbon price and the improvement of relative production costs.

\subsection{Breakthroughs in new energy technologies}

In this subsection we illustrate the potential impacts of more radical changes in the dynamics of renewable technologies and the role of abrupt technological breakthroughs on mitigation pathways through changes in the floor cost, which is a key parameter of the TFLCs in the POLES model.

While some observers argue that radical technological breakthroughs will be required to solve the climate challenge [35], others assume that existing technologies are sufficient to address the problem for the next half-century [35]. However most observers seem to agree on the need to significantly increase investment in energy technology R\&D. But R\&D activity is also a gamble which 
can lead to unexpected, stochastic outcomes; as such any deterministic model is limited in its ability to characterize its potential benefits, particularly regarding disruptive innovations. Deterministic models take into account neither uncertainty affecting future technology performances nor technological breakthroughs, by essence difficult to foresee. The difficulty identifying and predicting potential significant technological breakthroughs, in existing or new energy technologies, does not mean these breakthroughs are impossible. Indeed they may drastically change the outlook for technological competition and deployment of the various options.

The detailed treatment of new-technology dissemination in the POLES model, which describes the forces driving deployment of low-carbon technologies, enables us to test assumptions on breakthroughs and their consequences in terms of cost reduction and acceleration of the dissemination. In turn we may assess the impacts of radical innovations on the technology mix and the cost of mitigation policies. This is performed in the modelling exercises by reducing the floor cost for a given technology, a process which reflects drastic significant change in the technological frontier. In that perspective, we simulate the 450-FullTech-OPT AMPERE scenario while exogenously assuming a considerable reduction (50\%) in the floor costs for on- and off-shore wind, PV and CSP in the new 450-FullTech scenario with breakthroughs. It is thus possible to explore the potential impacts on the learning curves, the technology mix and policy costs ${ }^{7}$. Figure 13 displays several examples of breakthrough simulation with differentiated impacts depending on the position of the technology relative to the initial floor cost: in terms of technology costs, the impact at the end of the period remains limited for both wind technologies, while it is much greater for solar, PV and CSP.

\footnotetext{
${ }^{7}$ Because of mimesis effects in the adoption of a technology or to the existence of club goods and positive externalities in the dissemination of a technology, POLES model may also simulate some dissemination acceleration through the introduction of social network effects (tested for the first time into MENGHTECH project). While the model has been designed to account for the dissemination of incremental innovations, these social network effects are considered as particularly relevant for the considerably increasing the speed of dissemination of these radical innovations. Taking into account this new category of phenomenon may help in better analysing the potential impacts and defining the priorities regarding RTD strategies. This feature has been not taken into account in this exercise.
} 


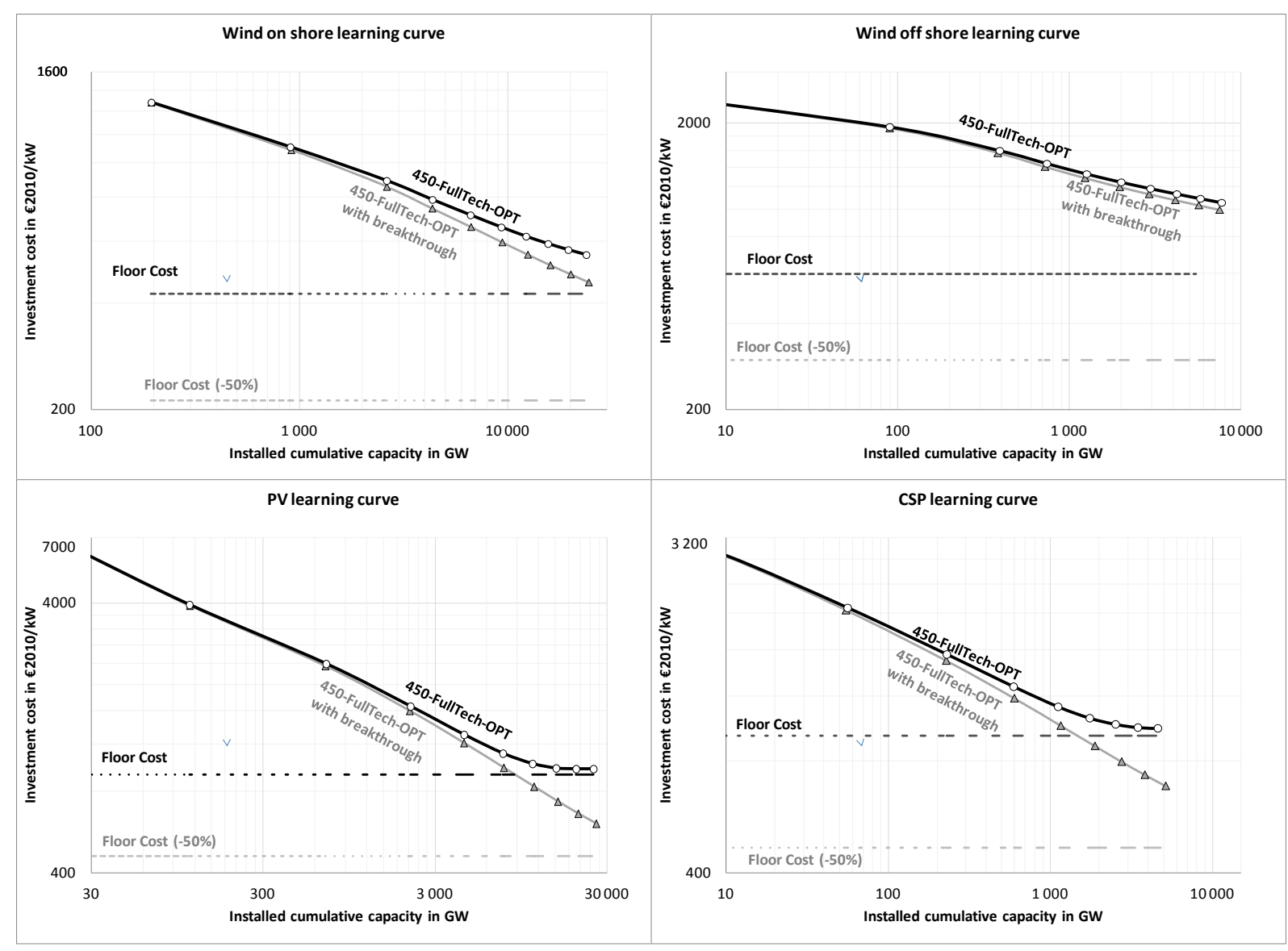

Figure 13: Impacts of breakthroughs on (lower technology floor costs) low carbon technology deployment

The main reason for such differentiated behaviour is the differences in the assumptions about learning rates for wind and solar technologies (see Table 2). For both on and off-shore technologies we assumed limited learning rates given those observed during the period 1980-2010 and the relative maturity of the technology. We assumed much higher learning rates for solar technologies which could potentially provide much higher reductions in investment costs. In the FullTech-OPT scenario, the effect of learning cannot fully operate as it is constrained by the floor cost. Removing this constraint makes room for additional cost reductions. The corresponding increase in power generation by 2100 is $+5 \%$ for $\mathrm{PV},+13 \%$ for CSP.

Due to the potential and deployment constraints integrated in the model, the impact on both wind technologies is much more limited in terms of additional installed capacity. By construction, constraints on technology deployment, such as resources and site availability or limits on variable renewable capacity development have been introduced which are stricter for wind than for solar 
technologies. For example, wind capacity development in POLES is limited by resource access (ie available land for wind farms) and the availability of installed dispatchable capacities, while PV is capped at $50 \%$ of captive electricity consumption in buildings which is a much lower constraint on capacity deployment. As a result, the deployment of cumulative wind capacity is limited and cannot attain the floor cost. In the breakthrough scenario, the decrease of the floor cost has no effect on learning because of the limits introduced by the electricity system on cumulative capacity. The absence of similar constraints for solar technologies allows it to benefit from unlimited learning with much lower costs and increased capacity.

\subsection{Extended versus compressed R\&D budgets}

This section addresses the issue of learning by considering changes in cumulative R\&D. For that purpose two R\&D scenarios have been designed:

1. A zero $R \& D$ scenario elaborated on the assumption that $R \& D$ budgets for the four technologies considered are withdrawn after 2015. This means a decrease of more than $80 \%$ of the total cumulative R\&D by the end of the period, as compared to the Baseline.

2. A high R\&D scenario based on a tenfold increase in $R \& D$ expenditure on the four technologies between 2015 and 2025. This means a more than 40\% increase in cumulative $R \& D$ in related technologies at the end of the period as compared to the Baseline. 


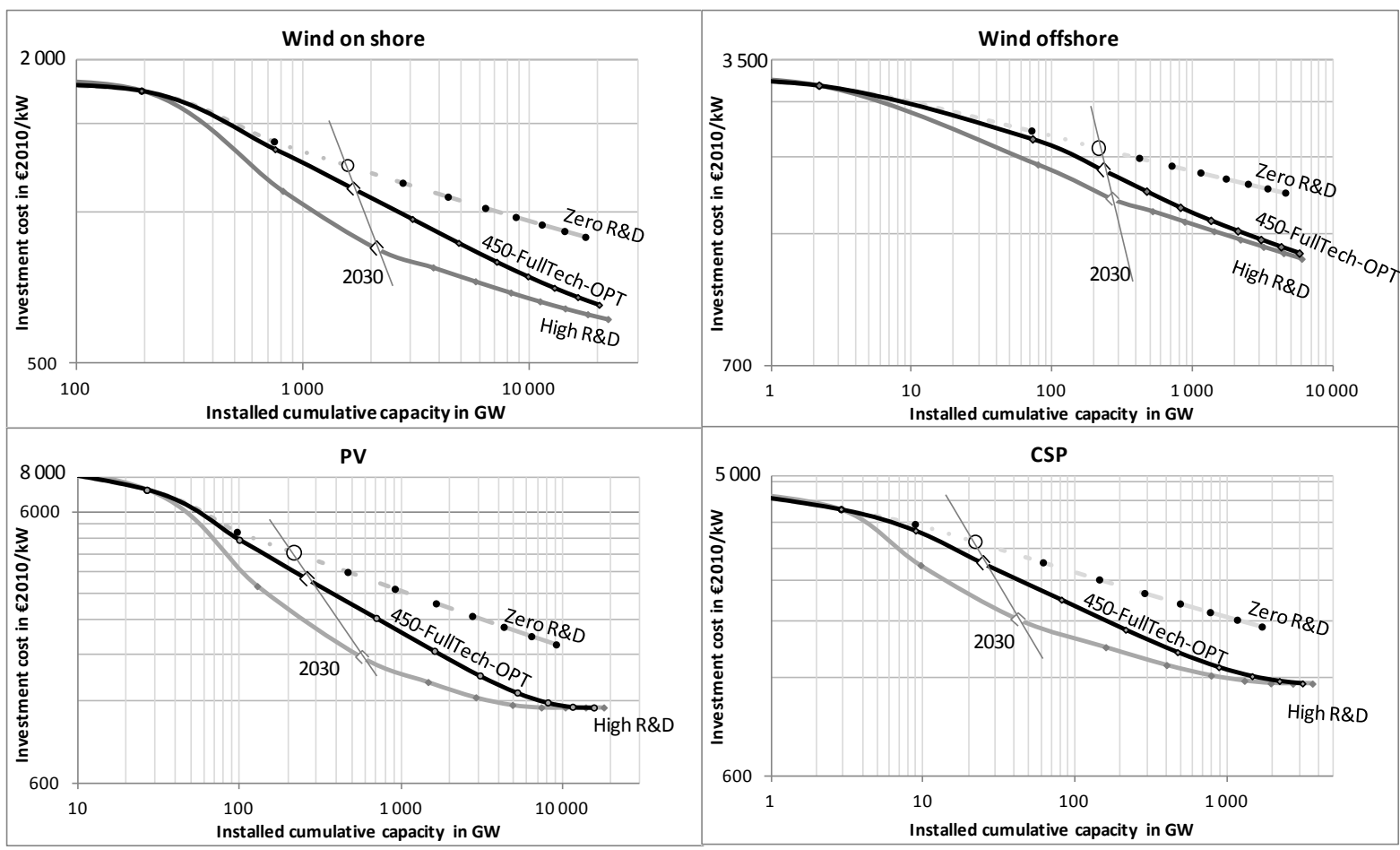

Figure 14: Impact of Scenarios on Technology Learning (curves in case of 450-FullTech-OPT, stop of R\&D and increase of

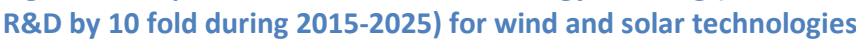

Figure 14 reports the learning curves of wind and solar technologies for three scenarios with different levels of R\&D. It shows clearly how changes in R\&D impact the capacities and investment costs of renewable technologies:

- the lower level of cumulative R\&D translates into a lower improvement of technology performances and lower deployment,

- conversely, the "High R\&D" scenario, based on a massive increase in R\&D budgets in 2015-25, accelerates improvements in the performance of technologies

Focusing on 2030, it is clear that for the scenario zero R\&D installed capacities are much lower than in the optimal and high R\&D scenarios for all technologies. Consequently investment costs are much higher in the scenario without R\&D than in other scenarios with more effort in R\&D.

In the longer term, the closer investment costs come to the floor cost, the less impact increased spending on R\&D has. In other words increasing R\&D has little impact on the investment cost by the 
end of the century. However, it is clear that reducing R\&D entails a heavy cost. As a result of withdrawing R\&D budgets, the investment cost at the end of the period is $50-70 \%$ higher for solar technologies and $36-38 \%$ higher for wind technologies in the "no R\&D" scenario in comparison with the benchmark, which of course hinders their dissemination.

Obviously, due to assumptions on learning rates, floor costs or constraints on deployment, the impact of R\&D varies for each technology. As we underlined in the section 5.2, solar technologies are assumed to have higher learning rates than wind technologies, consequently PV and CSP investment costs hit the floor cost at the end of the period. For the wind, it is related to capacity constraints. Essentially, this means that increasing R\&D has little additional benefit since no more wind farms will be built, even at slightly lower costs.

\section{The impact of learning on LCOE and mitigation costs}

The impact of learning is expected to lower the cost of each new energy technology taken individually and consequently limit the increase in the average production cost of electricity, even in scenarios with a strong carbon constraint. As electricity plays a crucial role in decarbonizing energy systems, this will in turn limit the cost of mitigation policies. Simulations with the POLES model of different scenarios with learning effects clearly illustrate this phenomenon.

In all the scenarios there is a marked convergence in the levelized cost of electricity (LCOE) of the renewable options between 2030 and 2050, towards or even below the average production cost of the electricity system (Figure 15). Learning in renewable options has a stabilizing effect on the average cost of electricity production in the long run, even if the average cost substantially increases in the medium term (2030) due to the introduction of a carbon price in the mitigation scenario. In the two 450 scenarios, the significant increase in the average cost of electricity in $2020-40$ results from two overlapping phenomena: i) the introduction of a high carbon price has an immediate impact on the cost of fossil-fuel generation, whereas the global electricity mix is still dominated by 
fossil energy sources (till 2030); ii) over the same period renewables are massively introduced into the electricity system, though their cost is still high, the full impact of learning effects not having been felt.

The large increase in the average cost of electricity production (up about 50\%) levels off after 2030 when the electricity mix changes with powerful deployment of non-fossil options, for which continuous learning is observed. During the $2020-50$ period, improvement in competitive conditions favour deployment of renewable technologies, including the less mature CSP and offshore wind. Accelerated learning allows a large decrease in the production costs of previously expensive renewables with a resulting fall in the global average cost. In the long run, the four scenarios illustrated in Figure 15 end with the average production cost of electricity stable at a level below $\$ 100 / \mathrm{MWh}$ in the pessimistic (i.e., LimSW) cases and $\$ 80 / \mathrm{MWh}$ in the FullTech cases, almost identical to the electricity system average cost in 2010 . This shows the impact of a $20 \%$ drop in the average cost of electricity from the pessimistic to the standard assumption for learning in the solar and wind options. One major outcome of these analyses is that, due to the learning effects, the deployment of low-carbon electricity options can be met at total costs that are comparable or even lower than those of the non constrained cases. 


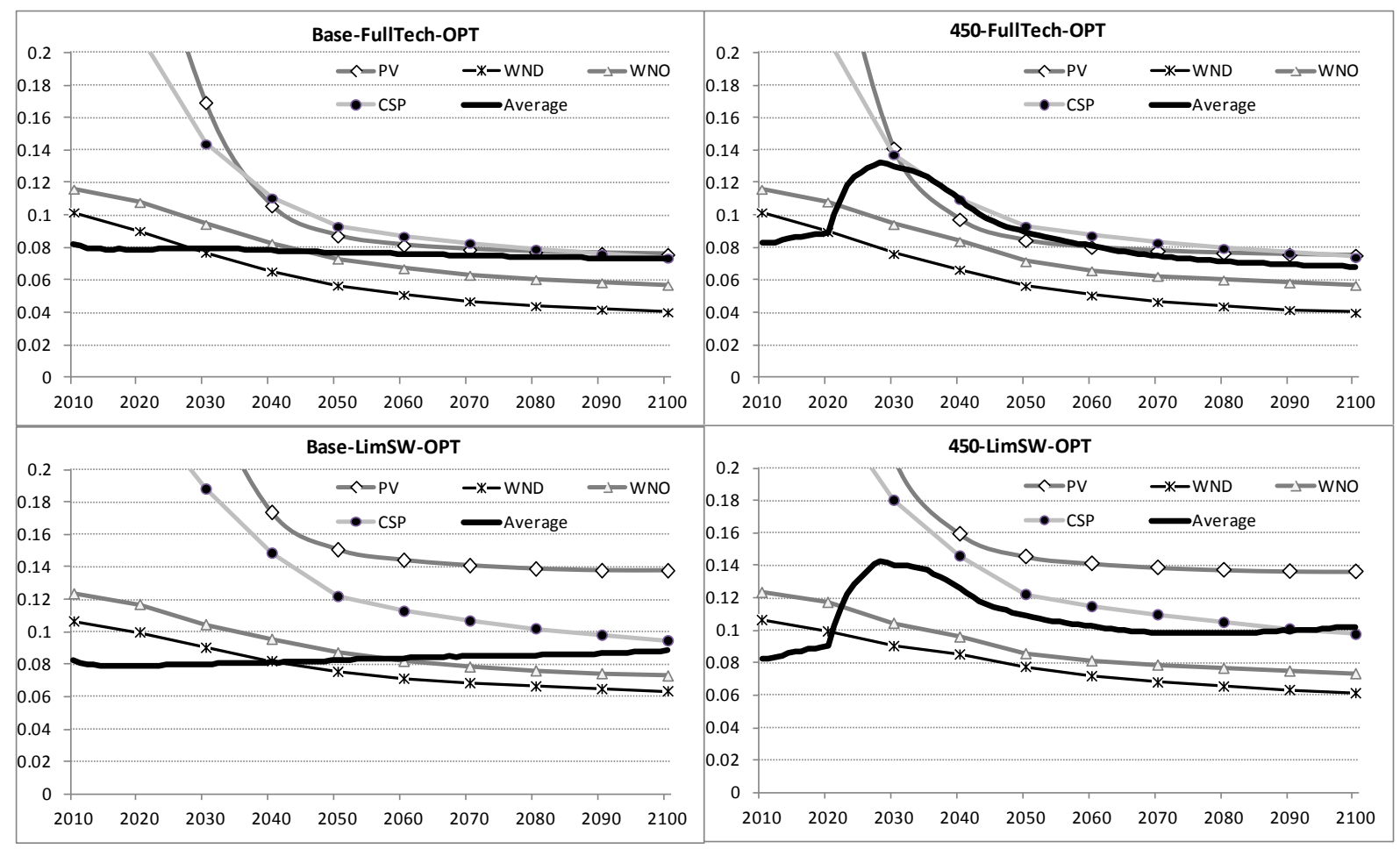

Figure 15: Levelized cost of electricity: renewable technologies and global mix

Despite their direct medium-term impacts on the electricity sector, the emission targets for 2030 are expected to be met at a relatively low cost, i.e. about $1 \%$ of Gross World Product. The marginal and total costs for the whole energy system increase in the long run, particularly in cases when one or more technology is not available or characterized by slow learning and cost/performance improvement (Figure 14). But these costs stabilize after 2050, when the bulk of the transition towards decarbonized energy systems will have been achieved. This consequently limits the weight imposed by climate policies on the world economy: after a peak at $2.5 \%$ of GWP in 2050 the abatement cost only represents $1 \%$ in 2100 , i.e. back to the 2030 level. 


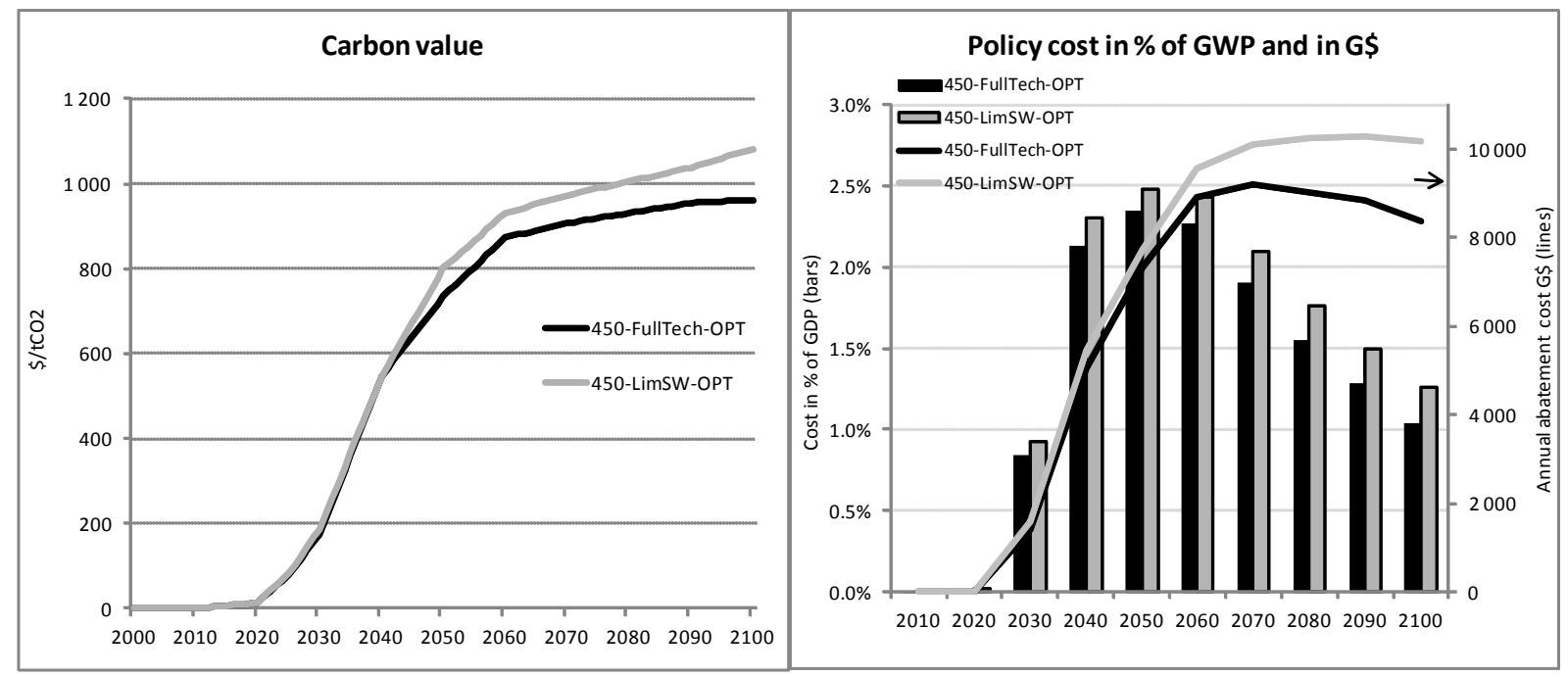

Figure 16: Marginal abatement cost curve (left), annual cost in absolute value and relative to GWP (right)

Regarding the impacts of the various AMPERE scenarios on these costs, the results indicate that the diversified character of the carbon mitigation portfolio is an important condition for the feasibility of climate stabilization at moderate cost. While the low energy-intensity case substantially reduces mitigation costs, failed or aborted development of one of the low-carbon supply options raises the cost of achieving the target, but to varying degrees, depending on the role of each technology in the FullTech case and its expected technological improvement. Table 6 illustrates the impacts of the scenarios considered on mitigation costs, compared to the 450-FullTech-OPT scenario.

Table 6: The impacts of LowEl, NucOff and LimSW (450-FullTech-OPT =100\%)

\begin{tabular}{|c|c|c|c|c|c|c|}
\hline & \multicolumn{3}{|c|}{ Carbon value (compared to 450-FullTech sc } & \multicolumn{3}{|c|}{$\begin{array}{l}\text { Policy Cost : Area under MAC Curve } \\
\text { (compared to 450-FullTech) }\end{array}$} \\
\hline & 2030 & 2050 & 2100 & 2030 & 2050 & 2100 \\
\hline 450-FullTech & $100 \%$ & $100 \%$ & $100 \%$ & $100 \%$ & $100 \%$ & $100 \%$ \\
\hline 450-LowEI & $80 \%$ & $55 \%$ & $80 \%$ & $70 \%$ & $52 \%$ & $64 \%$ \\
\hline 450-NucOff & $114 \%$ & $102 \%$ & $110 \%$ & $120 \%$ & $107 \%$ & $111 \%$ \\
\hline 450-LimsW & $109 \%$ & $102 \%$ & $115 \%$ & $111 \%$ & $106 \%$ & $121 \%$ \\
\hline
\end{tabular}

The main impacts of the various scenarios on mitigation costs can be summarized as follows:

- As noted by Riahi et al. [8], reducing energy intensity through greater energy efficiency is a major abatement option for reducing mitigation costs.

- The role of nuclear energy in the optimal mitigation trajectory decreases from $20 \%$ by 2030 to $10 \%$ by 2100 . In spite of its limited role in the benchmark, an $11 \%$ increase in the policy 
cost by 2100 , compared to the optimal case, must be expected in the case of a full nuclear setback.

- According to what has been observed above concerning the electricity sector, the scenario with conservative assumptions on solar and wind results in a $15 \%$ increase in the value of carbon and a $21 \%$ increase in the policy cost compared to the scenario $450-$ FullTech.

Renewables are critical for stabilizing the average electricity price in the long-term. The average electricity price is lower in the long-term in the 450-FullTech case than the Base case since there are more renewables in the electricity sector. However, when renewables are more limited and expensive (LimSW) the opposite occurs with average prices increasing with climate policy.

\section{Summary and conclusions}

The results of the POLES model runs presented in this paper explore various aspects of deploying new energy-technology and the associated learning processes, with various settings for energy and climate policies in the 21st century. It is clearly apparent from the various exercises that the learning process, which is integrated in all scenarios but with varying intensity and impacts particularly for new and renewable energy technologies, has a crucial role in limiting the costs of mitigation policies.

Looking back to past learning rates since the 1980s clearly shows that learning curves display nonlinear profiles: technology-development trajectories are sometimes slowed down, and at others accelerated specifically by technological progress and learning effects, but also by market conditions, industrial competition or changes in the prices of raw materials. This review of the past also provides a useful benchmark on a technology-by-technology basis, which for the purposes of validation enables analysis of model projections in the long run. 
The use of Two-Factor Learning Curves in the POLES modelling framework provides a simple representation of two key drivers of technological change: learning by doing and learning by searching. It also induces complex simulation properties, with apparent learning (the slope of the learning curve) being slower in mitigation scenarios with accelerated development: this is explained by the fact that a given level of deployment can be attained in a shorter time period, i.e. with less cumulative research and thus less learning by searching. Nevertheless, learning is indeed improved in the accelerated deployment scenario, because a given cumulative installed capacity and a given cost are reached in a shorter time.

Technological breakthroughs, as simulated through a reduction of the floor cost in the TFLC equations can have a major or a limited impact according to the deployment conditions of each technology family. In the current version of the model, constraints to the deployment of wind energy due to available resources and to the adequacy problem in the electricity system significantly limit the impact of a breakthrough on wind turbines, while the corresponding constraints seem less binding in the case of PV and CSP solar technologies. This probably calls for careful cross-technology examination of the nature and binding aspect of the resource and system constraints for the development of each technology.

As a broad conclusion of the R\&D analysis, the removal of the wind and solar R\&D budgets results in a major deterioration in the wind and solar investment cost reductions compared to the baseline. Conversely, the "High R\&D" scenario induces a significant improvement in the investment cost up to 2050, followed by a slackening in the end of the century, because of progressively converging cumulative R\&D budgets and of the narrowing gap between deployment constraints.

Similarly, the impacts of early versus delayed action differ depending on the parameters of the learning curve characterizing each technology. In all cases, of course, the low 2030 target induces an acceleration of deployment in the short to medium-term, but depending on the technology and the shape of its learning curve, the impacts on apparent learning are mixed. 
Finally examination of the impacts of learning on the electricity sector or on total abatement costs show that the improvement in technology costs and performances is an essential component in containing abatement costs in the very long run. Thanks to the learning effects, ambitious stabilization targets (450e) can be met with limited cost increases for the energy sector. In the long run, the levelized average cost of electricity production might even be lower in the constrained case than in the base case. In the mitigation cases, after a first wave of cost increases in the electricity sector, when low carbon technologies have not been fully deployed and have not reaped the full benefit of learning, costs decrease after 2030 in the electricity sector. The total energy-system cost increases over a longer period, but after the middle of the century, the marginal and total abatement costs stabilize, resulting in a decline of the global abatement costs from $2.5 \%$ in 2050 to about $1 \%$ of GWP in 2100. 


\section{Acknowledgements}

The authors acknowledge the support of the Assessment of Climate Change Mitigation Pathways and

Evaluation of the Robustness of Mitigation Cost Estimates (AMPERE) research project funded by the

European Union's Seventh Framework Programme FP7/2010 under grant agreement $n^{\circ} 265139$

(AMPERE) which enabled this paper to be written.

Many thanks to the reviewers for their meticulous reading and very pertinent comments, which helped us to considerably improve this paper.

\section{References}

[1] Schumpeter J., 1939, Business Cycles, , McGraw-Hill, New York.

[2] Grübler A., N. Nakicenovic, D. G. Victor, 1999, "Dynamics of energy technologies and global change," Energ Policy, 27, pp. 247-280.

[3] Arrow K., 1962, "Economic Welfare and the Allocation of Resources to Invention," RR Nelson Ed Princet. Univ. Press N. Y.

[4] Kouvaritakis, N., Soria, A., Isoard, S, 2000, "Modelling energy technology dynamics: methodology for adaptive expectations models with learning by doing and learning by searching. International Journal of Global Energy Issues," Int. J. Glob. Energy Issues, 14(1-4), pp. 104-115.

[5] Kobos, P. H., Erickson, J. D., and Drennen, T. E., 2006, "Technological learning and renewable energy costs: implications for US renewable energy policy," Energy Policy, 34(13), pp. 16451658.

[6] Miketa A., L. Schrattenholzer, 2004, "Experiments with a methodology to model the role of R\&D expenditures in energy technology learning processes; first results," Energ Policy, 32, pp. 16791692.

[7] Criqui P., N. Kouvaritakis, C. Thonet, 2000, "World post-Kyoto scenarios : benefits from accelerated technology progress," Int J Glob. Energy, 14(1-2-3), pp. $184-203$.

[8] Berglund and Sodërholm, 2006, "Modeling technical change in energy system analysis: analyzing the introduction of learning-by-doing in bottom-up energy models," Energy Policy 34.

[9] Wiesenthal T., P. Dowling, J. Morbee, C. Thiel, B. Schade, P. Russ, S. Simoes, S. Peteves,, and K. Schoots, M. Londo, Technol. Learn. Curves Energy Policy Support JRC Sci. Policy Rep. ECN, p. 2012.

[10] Nemet G. F., 2012, “Inter-technology knowledge spillovers for energy technologies," Energy Economics. 34.

[11] Clarke L., J. Weyant, J. Edmonds, 2008, "On the sources of technological change: What do the models assume," Energy Economics, 30.

[12] Lindman A., P. Söderholm, 2012, "Wind power learning rates: A conceptual review and metaanalysis," Energy Economics, 34.

[13] Panzer C., 2012, "Investment costs of renewable energy technologies under consideration of volatile raw material prices."

[14] Yeh S., E. S. Rubin, 2012, "A review of uncertainties in technology experience curves," Energy Economics, 34. 
[15] Riahi K.; E. Kriegler; N. Johnson; Ch. Bertram; M. den Elzen; J. Eom; M. Schaeffer; J. Edmonds; M. Isaac; V. Krey; T. Longdon; G. Luderer; A. Mejean; D. L McCollum; S. Mima; H. Turton; D. van Vuuren; K. Wada; V. Bosetti; P. Capros; P. Criqui; M. Hamdi-Cherif; M. Kainuma; O. Edenhofer, "Locked into Copenhagen pledges - Implications of short-term emission targets for the cost and feasibility of long-term climate goals," Technol. Forecast. Soc. Change Press Corrected Proof Available Online 27 Novemb. 2013.

[16] Eom J., J. Edmonds, V. Krey, N. Johnson, K. Riahi, D.P. van Vuuren,, 2013, "The impact of nearterm climate policy choices on technology and emissions transition pathways," Technol. Forecast. Soc. Change.

[17] McDonald, A. and L. Schrattenholzer, 2001, "Learning Rates for Energy Technologies," Energy Policy 33, 29, pp. 255-261.

[18] Rubin, E. S., Yeh, S. et al, 2007, "Use of experience curves to estimate the future cost of power plants with CO2 capture.," Int. J. Greenh. Gas Control, 1(2), pp. 188-197.

[19] Neij. L, 2003, "The Development of the Experience Curve Concept and its Application in Energy Policy Assessment.," Energy Technol. Policy, 2, pp. 3-14.

[20] Wene, C.-O, 2000, "Experience curves for energy technology policy."

[21] Junginger, M., van Sark, W., Faaij, A. (Editors), 2010, “: Technological Learning In The Energy Sector, Lessons for Policy, Industry and Science."

[22] Ferioli, F., Schoots, K and van der Zwaan; B.C.C, 2009, "Use and Limitations of Learning Curves for Energy Technology Policy: a Component-Learning Hypothesis.," Energy Policy, 37, pp. 25252535.

[23] Yu C.F., W.G.J.H.M. van Sark, E.A. Alsema, 2011, "Unraveling the photovoltaic technology learning curve by incorporation of input price changes and scale effects."

[24] Nemet G, Kammen D, 2007, "U.S. energy research and development: declining investment, increasing need, and the feasibility of expansion.," Energy Policy, 35(1), pp. 746-755.

[25] Van der Zwaan, B.C.C. and Wene, C.-O., 2011, "Developments in Interpreting Learning Curves and Applications for Energy Technology Policy.," Theory Models Appl. M Jaber Ed Taylor Francis N. Y., pp. 425-443.

[26] Bolinger M., Wiser R., 2011, “Understanding Trends in Wind Turbine Prices Over the Past Decade,"

[27] Kitous, A., Criqui, P., Bellevrat, E., Chateau, B., 2010, "Transformation Patterns of the Worldwide Energy System - Scenarios for the Century with the POLES Model. vol. 31, Special Issue $n^{\circ} 1$ on The Economics of Low Stabilization, pp. 57-90 pdf.," Energy J.

[28] Russ P., Criqui P., 2007, "Post-Kyoto $\mathrm{CO} 2$ emission reduction : the soft landing scenario analysed with POLES and other world models.," Energy Policy Vol 35 N², pp. 786-796.

[29] Kouvaritakis N. , A. Soria, S. Isoard, 2000, "Modelling energy technology dynamics: methodology for adaptive expectations models with learning by doing and learning by searching," Int J Glob. Energy, pp. 104-115.

[30] Criqui P., Mima S., 2002, "Technology Improvement Dynamics for power generation technologies and R\&D objectives measurement."

[31] CRIQUI Patrick, MIMA Silvana, 2008, "Model extensions to represent hydrogen economy configurations into POLES model."

[32] Criqui Patrick, Mima Silvana, 2008, "Results of the climate and energy policy analysis with the POLES model," Rep. "Modelling Energy Technol. Prospect. Gen. Partial Equilib. Framew.MENGTECH" Proj. Res. Proj. DG RES 6th Framew. Programme, p. 51.

[33] Tavoni M. , E. De Cia, G. Luderer, J.C. Steckel, H. Waisman, 2012, "The value of technology and of its evolution towards a low carbon economy," Clim. Change, 114, pp. 39-57.

[34] Krey V., L. Clarke, 2011, "Role of renewable energy in climate mitigation: a synthesis of recent scenarios," Clim. Policy, 11, pp. 1-28.

[35] Hoffert M.I., et al, 2002, "Advanced technology paths to climate stability: energy for a greenhouse planet," Science, 298, pp. 981-987. 
[36] Pacala S., R. Socolow, 2004, "Stabilization Wedges: Solving the Climate Problem for the Next 50 Years with Current Technologies," Science, (305).

Dr. Patrick CRIQUI is a senior researcher at CNRS and head of the Economics of Sustainable Development and Energy group (PACTE-EDDEN, CNRS, Univ. Grenoble Alpes). He developed a long-term world energy model, POLES, which is currently used by the European Commission and by various administrations and companies in Europe to analyze the economics of climate policies. He was a lead author in IPCC's Working Group 3. He is a member of the Economic Council for Sustainable Development by the French Minister of Ecology and of the scientific council of the Local Climate Action Plan of the Grenoble metropolitan area.

Dr. Silvana Mima is a CNRS Research Engineer at PACTE-EDDEN, where she contributes to developing, maintaining and using the POLES model on the transformation of the energy system towards a low-carbon economy and estimation of climate change impacts in the energy sector. She is also interested in new energy technology developments (fuel-cells, hydrogen, carbon capture and sequestration, renewables), energy markets and policy analysis. She has taken part in many of the research programmes of the institute, particularly in several EU Commission's Fifth, Sixth and Seventh Framework Programme projects (WETO-H2, SAPIENTIA, CASCADE-MINTS, MENGHTECH, SECURE, ADAM, Climate Cost, AMPERE, etc.)

Dr. Philippe Menanteau is a CNRS Research Engineer at PACTE-EDDEN, a graduate of the Ecole Spéciale des Travaux Publics and a doctor in Energy Economics of the Institut National des Sciences et Techniques Nucléaires. His main research activity focuses on technological change in the energy sector and analysis of policies and measures to disseminate new energy technologies. He is also in charge of developing the energytechnology databases used in the prospective scenarios using the POLES energy system. 
Alban Kitous is a specialist on energy policy assessment and economic modelling. He is currently working on these topics as a scientific officer at the European Commission (JRC IPTS). He started his career as an analyst in the French research institute CNRS-IEPE and then set up the Global Energy Forecast team within the consultancy ENERDATA. Of French nationality, Alban holds a MSc on Environmental Technology (ICCET) and a degree in engineering. 